\title{
Omni-channel integration: the matter of information and digital technology
}

\author{
Soroosh Saghiri and Vahid Mirzabeiki
}

\begin{abstract}
Purpose: This paper aims to explore how omni-channel data flows should be integrated by specifying what data, omni-channel agents, and information and digital technologies (IDTs) should be considered and connected.
\end{abstract}

Design/methodology/approach: A multiple case study method is employed with 17 British companies. The studies are supported by 68 interviews with the case companies and their consumers, five site visits, four focus group meetings, and the companies' archival data and documentations.

Findings: This paper provides novel frameworks for omni-channel data flow integration from consumer and business perspectives. The frameworks consist of omni-channel agents, their data transactions, and their supporting IDTs. Relatedly, this paper formalizes the omni-channel data flow integration in the forms of horizontal, vertical and total integrations, and explores their contributions to the adaptability of omni-channel, as a complex adaptive system (CAS). It also discusses that how inter-organizational governance mechanisms can support data flow integration and their relevant IDT implementations.

Originality: This research's recommended frameworks provide a robust platform to formalize data flow integration as the omni-channel's core driver. Accordingly, it moves the literature from a basic description of "what omni-channel is", and provides a novel and significant debate on what specific data should be shared at what levels between which agents of the omni-channel, and with what type of relationship governance mechanism, to assure omni-channel horizontal, vertical and total integrations.

Research implications: The breadth and depth of the required IDTs for omni-channel integration prove the necessity for omni-channel systems to move toward total integration. Therefore, supported by CAS and inter-organizational governance theories, this research indicates how data flow integration and IDT can transform the omni-channel through self-organization and autonomy capability enhancement.

Keywords: Omni-channel, Data flow integration, Information and Digital Technology (IDT), Complex Adaptive System, Inter-organizational governance. 


\section{Omni-channel integration: the matter of information and digital technology}

\section{Introduction}

The retail operations management have increasingly become consumer-led, while they need to respond to the diverse and varying market demand in an omni-channel environment (MacCarthy et al., 2016). The omni-channel retailing aims to achieve a seamless and uniform view of the physical and data flows across its agents (e.g. retail shop, delivery service, and data service provider), while providing various channels (e.g. online and offline) for consumers to find, buy, deliver and return the product (Saghiri et al., 2017).

The existing body of knowledge has highlighted synchronization, visibility and integration as the main drivers of the omni-channel management (Cai and Lo, 2020; Melacini et al., 2018). Numerous studies address specific needs for data management and integration between online and offline stores (Herhausen et al., 2015; Verhagen and van Dolen, 2009), across multiple firms' Enterprise Resource Planning (ERP) systems (Sousa and Voss, 2006), among different stock-keeping points (Barratt et al., 2018), and within warehouses (Onal et al., 2018). Empirical and sectoral studies, for example in grocery (Müller-Lankenau et al., 2006), clothing (Kembro and Norrman, 2019b) and banking (Patel, 2014), also underscore the crucial role of data integration in the omni-channel system. Notwithstanding the prevailing emphasis on omni-channel integration, the literature on "how" to make integration happen is still nascent. Managerial and visionary monographs (e.g. Briedis et al., 2019) report a high level of data inconsistency and inaccuracy in omni-channels, and scholarly research demands further research in this area (Caro et al., 2020).

To manage data flows and the required integrations allied to them, retail operations management have already employed a wide range of information and digital technologies (IDTs) such as barcode, radio frequency identification (RFID) and electronic data interchange (EDI) (Dai and Tseng, 2012; Vize et al., 2013). However, IDT has significantly developed in recent years, and the application of more advanced technologies such as cyber-physical systems (CPS), Internet-of-Things (IoT), artificial intelligence (AI) and big data analytics (BDA) are yet to be explored in the omni-channel context. The outstanding and rapidly expanding capacity of IDT in capturing, analyzing, and synchronizing data fits very well with the increasing complexities around omni-channel integration (for details, see the literature review in Section 2). Nevertheless, the major relevant studies do not acknowledge the IDT centrality for omni-channel management (Seyedghorban et al., 2020), and there is a need for more studies on omni-channel integration with a particular focus on advanced IDT and their impact on omnichannel performance (Cheng et al., 2015). This need has been also stressed earlier by Oh et al. (2012), calling for studies on embedding mobile channels within delivery systems, and more recently by Chi et al. (2020) and Pereira and Frazzon (2021), highlighting the need for research on digital-physical retail integration and governance. This paper responds to these calls by providing a comprehensive exploration of how to enhance omni-channel data flow integration, using IDT, through extensive multiple case studies of 17 companies. The case studies include and are supported by 68 interviews, 
five site visits, companies' archival data and documentations, and four focus groups (see Section 3 for details). This explorative research aims to answer the following research questions:

(i) How should omni-channel data flows be organized (i.e. what data, what omni-channel agents, and what type of IDTs) to operationalize omni-channel integration in both consumer and business sides?

(ii) How may IDT support the omni-channel data flow integration?

(iii) How does data flow integration contribute to the omni-channel system adaptability, and how can inter-organizational governance support data flow integration?

Through answering these questions, the paper offers the following contributions to the literature.

First, by determining the data transactions across the omni-channel retailing, this research offers novel data flow frameworks for the consumer and business sides of the omni-channel system. The frameworks provide a robust platform (based upon consumer shopping journey and retailer order fulfilment process models presented in sub-Sections 4.1 and 4.2) to formalize data flow integration, as the core driver of the omni-channel management.

Second, the recommended data flow frameworks materialize data flow integration in a threefold way: horizontal, vertical and total integration. More specifically, this research offers empirical evidence to manifest what data should be shared at what levels and between which agents (such as retail shop and warehouse) of the omni-channel system to assure total integration.

Third, this research identifies a number of conventional and advanced IDTs required to manage the omni-channel data flows, and to make the total integration happen. In particular, the breadth and depth of the required IDTs for omni-channel integration prove their necessity for omni-channel systems.

Fourth, looking at the research analysis and outcomes, from the complex adaptive system (CAS) (Miller and Page, 2009) and inter-organizational governance (Mahapatra et al., 2010) theory lenses, this research demonstrates how inter-organizational governance mechanisms across the omni-channel system may support data flow integration, and how data flow integration contributes to omni-channel adaptability (against its complexities and uncertainties). Recognizing the omni-channel retailing as a CAS, this research argues that data flow integration and its supportive IDT positively contribute to the omni-channel adaptability against its inherent complexity, including large-scale inter-connections, diversity, heterogeneity, dynamism, and non-linearity. In particular, it is shown how data flow integration and IDT can transfer the omni-channel system through self-organization capability enhancement, where its well-integrated agents can make autonomous decisions and take real-time actions, with sufficient visibility of the product, production, storage, shipments, and return data. Furthermore, the implementation of omni-channel data flow integration and its supportive IDTs are found to be dependent on inter-organizational relationship governance. More specifically, this research discusses that contractual and relational governance mechanisms (see sub-Section 2.3 for further details) are complimentary to deploy IDT implementations toward achieving horizontal, vertical and total omni-channel integrations - the concepts that are introduced and formalized in this paper.

The rest of this paper is organized as follows: Section 2 reviews the literature and provides a theoretical ground for the research. Section 3 presents the research methods in detail. Sections 4 and 5 share the findings of the research and propose the IDT-supported data flow frameworks for the omni-channel 
system. Finally, theoretical and practical contributions of the paper, and suggestions for future research are provided in Section 6.

\section{Literature review and theoretical ground}

\subsection{Omni-channel and integration issues}

While multi-channel retail has traditionally tried to provide the consumer with more sales and delivery options (e.g. online and offline), it ends up with fragmented and disjointed product stocks, sales strategies, inventory data, and delivery plans (Verhoef et al., 2015). The omni-channel concept, developed through the retail, logistics, marketing and supply chain research over the last two decades (e.g. Avery et al., 2012; Lim and Srai, 2018), has tried to overcome the inefficiencies and pitfalls of multi-channel retail (Cai and Lo, 2020).

The omni-channel retailing claims to offer full visibility across all channels and a uniform shopping experience to consumers, regardless of the sales channel (Bell et al., 2015). To achieve these, full integration among physical and data flows is needed, where virtually all omni-channel agents can see and share product, inventory, sales and/or logistics data throughout the omni-channel system (Sousa and Amorim, 2018; Wollenburg et al., 2018b). This needs interconnected agents such as physical store, online sales, distribution center, and manufacturer (Li et al., 2018), and well-defined integration plans (Mirzabeiki and Saghiri, 2020). The concept of integration benefits from a wealth of knowledge in operations and information management literature. Among them, Oh et al. (2012), Chen et al. (2013), and Liao et al. (2017) provide exhaustive abstract frameworks for integration, relevant to the omnichannel. Oh et al. (2012) organize integration according to the function (e.g. integrated sales, promotion and marketing). Chen et al. (2013) view omni-channel integration in a hierarchy of physical, application and business integration levels. Finally, Cao and Li (2018) indicate the positive impact of information technology capabilities on omni-channel integration. A summary of the relevant literature on omnichannel integration and its requirements, opportunities, challenges, and impacts is provided in Appendix 1.

\subsection{IDT applications and omni-channel research gaps}

To manage product and data flows, omni-channels have tried various technologies, specifically IDT. The literature review of this research also investigates a number of potential IDT applications in product identification, and Business-to-Business (B2B) and Business-to-Consumer (B2C) data transactions.

Product data are core for omni-channels (Acquila-Natale and Iglesias-Pradas, 2020), and need to be retrieved, monitored, and updated from manufacturer to retailer (Sun and Tyagi, 2020). Barcodes and RFID are two well-established data recording and capturing technologies, used in various picking, storage, shipping and delivery operations. Barcodes, readable by scanners, and RFID tags, with the capability of being both readable and writable (in passive and active forms), help users identify and locate products swiftly and accurately (Fan et al., 2015). They facilitate product shelf-replenishment (Condea et al., 2012), and can save operational costs for omni-channels (Dai and Tseng, 2012). 
Contemporary identification devices such as smart sensors go beyond basic product information, and capture more dynamic data, such as product temperature, freshness, and status via smart packaging, smart containers, and smart shipment (Bogataj et al., 2017). More advanced product detection technologies, equipped with shape/object identification and AI can make product identification across the omni-channel retailing very thorough (with full static and dynamic product data), virtually $100 \%$ accurate, and available on a real-time basis (Sun et al., 2020). Working together, identification technologies collectively enable automated information flows and therefore stock traceability, control and optimization - in terms of quantity and location (Chen et al., 2013). With wider levels of agreement between retailers and other omni-channel agents on using the same identification standard (e.g. Global Standard barcodes - GS1, 2015), those technologies can become strong enablers for a universal product stock and demand management within the omni-channel system, which facilitates coordination and integration among omni-channels' business units.

B2B transactions, mainly between buyer and seller, are facilitated by essential, well-established platforms such as EDI (Ettlie et al., 2005), supporting order placement and receipt, purchase order, shipment notice, delivery notice, invoicing, and payment. The conventional EDI has been enhanced to e-business and Internet systems, such as cloud-based EDI, to support fast, accurate, and large volumes of data transactions, not only between one buyer and one seller, but also among a wider range of supply chain and logistics agents of omni-channel systems (Vize et al., 2013). These real-time data transmissions help omni-channel agents to receive the data they need, make timely decisions, and move toward integrated physical flows (Hofmann and Rüsch. 2017). Common errors and delays, which typically happen due to manual intervention, are minimized by B2B IDTs. This reduces reworks, buffer times and buffer inventories, and makes omni-channels more efficient and less costly (Craig et al., 2015).

With the expansion of data generation and capturing nodes, and data transactions among them, the new concept of IoT has emerged. IoT refers to a highly distributed network of devices, communicating with each other and their users (Ancarani et al., 2020). IoT, assisted by Wireless Sensor Networks (WSN) and the Internet, can widely support B2B integration schemes such as information sharing, collaborative warehousing, automated ordering and replenishment, and vendor managed inventory (Ivanov et al., 2020), which help the omni-channel system have greater visibility of its products, coordinate the products' inventories and make them available efficiently and flexibly in different channels on demand.

B2C transactions are also supported by IDT applications mostly around electronic-commerce systems (King et al., 2004), which have extended to highly advanced technologies such as mobile apps with location recognition, data capturing, and payment capabilities (McLean, 2020). The main purpose of ecommerce systems is to involve consumers in the omni-channel processes (e.g. order fulfillment shipment, and returns), to not only facilitate their shopping experience, but also maintain the relationship with them in the long-term (Zhang et al., 2018). This may include updating consumers with the latest news about products which have been previously purchased by them (e.g. new features, warranty services, or recalls), informing consumers about new products, involving them in market surveys, and even monitoring their latest shopping behavior, status and needs (Li et al., 2020; Margetis et al., 2019). More advanced IDTs such as virtual reality and augmented reality try to enhance the consumer experience and engagement, and integrate the online and offline aspects of the omni-channel retailing even further (Heller et al., 2019). 
On the production side of the omni-channel system, advanced technologies in manufacturing, assembly and packaging have significantly increased companies' abilities in making product in small volumes and more flexibly (Khanchanapong et al., 2014). In particular, robotic and CPS try to coordinate computer programs with physical objects, devices, and machines (Leitao et al., 2016), assist firms to manage and control various operations autonomously, and eventually enhance production performance in terms of time, quality and adaptability (Xu et al., 2018). In such a smart, integrated production, machines can interact with each other using WSN (Strozzi et al., 2017) to implement the production plans, where the ERP system can receive and process all shop floor data instantaneously, and update the plans accordingly (Hald and Mouritsen, 2013). This can give omni-channel systems real-time access to and uniform visibility of their operations (e.g. manufacturing, storage, and delivery), distributed among different channels, and help them plan their stock movements more efficiently. Moreover, advanced, smart manufacturing technologies can enable omni-channels to make more customized products for different channels based on those channels' specific needs (Zhang and Zheng, 2020).

Advanced IDTs such as BDA, AI, and IoT, as mentioned briefly earlier, may have wider applications across the omni-channel processes. Although there is no omni-channel-specific research on those applications, there are studies that address how advanced technologies are implemented in various functions of omni-channel systems (e.g. warehousing). The expanding usage of IDTs in various agents and operations of the omni-channel retailing has led to enormous amounts of data, generated and shared by sensors, scanners, and data exchange and transmission instruments. These data can be a valuable source of knowledge if mined and analyzed properly (Villalobos et al., 2020). BDA, using advanced analytical and computing techniques to synthesize large and heterogeneous data sets, can provide various descriptive, predictive and prescriptive analyses (Brinch, 2018). They, (a) on the consumer side, help the omni-channel retailing understand the market trends, preferences, and behavior at the segment, channel, and even individual consumer level (Jocevski, 2020), and (b) on the business side, support the omni-channel complex decisions and actions around when and where to order, make, hold and move the products (Wamba and Akter, 2019).

Very much coupled with BDA, AI has been increasingly used in market and consumer behavior analysis and e-commerce (Singh and Tucker, 2017), order management and locating the order status (Hofmann and Rüsch 2017), order pick-up and delivery scheduling and routing planning with time, cost, air pollution, and consumer satisfaction optimization objectives (Kang et al., 2019), and operations improvement and lean supply chain (Liu et al., 2013).

In summary, the quite disjointed use of advanced IDTs, such as IoT, AI and BDA, in different parts and processes of the retail business, as well as the great opportunities of those technologies to contribute to the omni-channel retailing (Bradlow et al., 2017), highlight the demand for new studies on the specific applications of IDTs collectively (conventional and advanced ones) to omni-channel data integration, decision and actions (as explained in the sub-Section 2.1). These specific gaps have been also emphasized in very recent literature reviews by Cai and Lo (2020) and Seyedghorban et al. (2020), who call for explorative research on channel integration and the technology applications which transform the omni-channel retailing. 


\subsection{Theoretical anchor}

The explorative approach of this paper can synthesize and explain its outcomes in omni-channel data flow integration frameworks better as it comprehends the omni-channel phenomenon through theoretical lenses. In light of that, this research relates the omni-channel concept to the complex adaptive system (CAS) (Miller and Page, 2009) and inter-organizational relationship governance (Cao and Lumineau, 2015) theories. The use of two theories, found to be complementary, allows the research to understand the phenomenon from different perspectives, hence providing more in-depth evaluations and insights.

Scholars and practitioners have already raised the need to manage omni-channel as a system (Wollenburg et al., 2018a). But, its highly dynamic and complex nature, as discussed below, calls for a broader view to omni-channel, where CAS is an appropriate lens for it. Greatly in line with the CAS attributes, the omni-channel's numerous agents of generating, capturing and sharing data in multiple channels, and also the countless amounts of data, generated by and exchanged between them, while they are changing dynamically, make the omni-channel retailing a truly complex system. Meanwhile, the omni-channel competences in, for example, managing order fulfillment and switching products from one channel to another, to respond to constantly changing consumer demand, supports its adaptability. This paper links omni-channel retailing to CAS and theorizes it through five properties:

(i) A large number of inter-connected agents as the main feature of CAS (Nilsson and Darley, 2006), is very much applicable to omni-channel retailing. Following Haki et al. (2020), several data generation/capturing/ sharing agents of the omni-channel system are considered as agents, in the two forms of actors (e.g. retail store, online retailer, logistics service, and manufacturer) and IT applications (e.g. replenishment systems, and e-commerce packages), which should be connected and synchronized. This connectivity (e.g. the case of online-offline showrooming: Zhang et al., 2020a) is a core feature of the omni-channel system, which distinguishes it from conventional retail systems (e.g. bricks \& mortar or multi-channel).

(ii) Diversity and heterogeneity apply to omni-channel agents and their multiplicity, while each agent may have various roles and objectives (Nilsson and Darley, 2006). They also refer to an extensive range of interactions among the agents. While conventional retail systems have limited interactions with suppliers and delivery services, omni-channel systems should manage a quite diverse range of physical/information/financial transactions, associated with payment, delivery, product exhibitions, stocking, manufacturing and returns processes, in various channels synchronously (Verhoef et al., 2015).

(iii) Dynamism refers to frequent changes in the agents' activities and objectives (e.g. a warehouse may switch its role from a stock-keeping point to a solution provider entity for retailer (Kembro and Norrman, 2019b), or logistics service providers support the healthcare system to collect Covid-19 tests (Mooney, 2020), which may cause changes in their interactions with other agents, and add to the system complexity.

(iv) Non-linearity is grounded in the disproportional effects of changes in one agent (and its connections) on other agents and interactions. Non-linearity is found influencing and influenced by the interconnectedness, heterogeneity and dynamism of the system (Choi et al., 2001). Various cases of non-linearity are traceable in the retail sector which indicate how the omni-channel retailing is different from conventional retail models - for example, a negative feedback in online channel might significantly and positively increase the demand in other channels (Berger et al., 2010), or major breakthrough 
changes in mobile shopping technology might have a minimal impact on cash buyers of the store channel.

(v) Adaptation through self-organization and emergence, as a key property of CAS to manage complexities, is of great significance for the omni-channel system. At the system level, omni-channel retailing needs to cope with and manage its changes internally (e.g. in data and physical flows among the agents) and externally (e.g. in demand, supply, business environment, and regulations). At the entity level, omni-channel agents need to spontaneously modify their internal business processes and external interactions (with other agents) to respond to heterogenous and dynamic changes imposed to them by other agents or the external environment (e.g. see the logistics model restructuring case, proposed by Marchet et al., 2018). The agents' capabilities to structure/restructure their business processes and interactions define their self-organization property, highly required for adaptability of CAS. The omnichannel agents' self-organization capabilities should collectively lead to emergence of new flows, interactions or settings for the whole omni-channel system (e.g. see the case of omni-channel adaptation to the changes in the consumer shopping journey during Covid-19: Zhang et al., 2020b), which is also a key for CAS adaptability.

Drawing on the properties above, data flow integration and its assisting IDT are expected to enhance the omni-channel adaptability.

Managing and integrating diverse and large-scale data flows across the omni-channel system, and implementing IDTs to support them, need engagement of omni-channel agents and their encouragement toward further integration and IDT application. Therefore, this research views the omni-channel data flow integration in the inter-organizational relationship context and its relevant governance mechanisms (Akin Ates et al., 2015), that drive data flow integration and its supporting IDT implementation. Governance is defined as the coordination and control of economic exchange among organizations (Mahapatra et al., 2019), and typically implemented through contractual and relational mechanisms (Um and Oh, 2020). Contractual governance focuses on determining the rights, responsibilities and control procedures in a relationship, and relational governance is mainly defined around collaboration, trust and joint problem solving (Cao and Luminea, 2015; Mahapatra et al., 2010). In view of them, the paper discusses how cases of data capturing instruments (e.g. smart sensors), data sharing platforms (e.g. WSN and WWW), horizontal and vertical data exchange technologies (e.g. IoT and CPS), autonomous planning units (supported by AI) and advanced data analysis methods (BDA) need one or both contractual and relational governance across the omni-channel system.

\section{Methods}

\subsection{Research setting}

This study adopts a multiple case studies design (Stake, 2013), which fits well with the explorative approach of this research, and leads to an in-depth understanding about the emerging phenomena of IDT, data flow integration and omni-channel retailing as a complex system.

Following Miles et al. (2013) recommendations, the sampling frame in this multiple case study research is guided by the research questions. Purposive sampling (Ellram, 1996; Flick, 2009; Miles et al., 2013) in stratified form (Marshall and Rossman, 2006: p71) is used, enabling developing a rich and comprehensive theoretical framework on application of IDTs, by considering perspectives of the key 
agents in omni-channels (sub-groups in stratified sampling), i.e., manufacturers, wholesaler, logistics companies, retailers, and data service/IDT providers. Based on this frame, the criteria defined by the researchers for selecting the cases are: first, their position as leading organizations who have a significant share and influence in their sectors; second, being part of an omni-channel system (i.e. interacting with a number of businesses such as manufacturing firms, sales, logistics, and information services, who are performing in an inter-connected way in multiple channels); third, having a strategy or plan for the digital transformation of their omni-channels and investing in IDT for their operations (e.g. by using technology and standards for capturing and sharing data on products and operations); and, fourth, providing the researchers with sufficient access to data, illuminating the research questions (Yin, 2014).

The sample includes 17 leading British companies, who are parts of omni-channel systems, with multiple manufacturers, distributors, logistics service providers, and data service/IDT providers, performing in multiple inter-connected channels. This number of cases ensures generalizability of findings in this case study research (Eisenhardt, 1986).

The definition of the 'unit of analysis' in case study research is related to the research questions of the study (Yin, 2014). The research questions of this paper (presented in the introduction section) are about IDT-enables data flow integration (across omni-channel processes), its contribution to omni-channel, and inter-organizational relationship mechanisms to support it. Therefore, the unit of analysis of this research is the 'omni-channel system' of each of the studied companies, while the focus is on data flows among each company and other agents of the omni-channel, where that company is a member of.

Information about the case companies is provided in Table I. Having an extended view of different companies, who perform as different agents (e.g. manufacturer, wholesaler, logistics provider, retailer, and IDT provider) in different omni-channels, supports the breadth and depth of this research in operationalizing the omni-channel integration and understanding the opportunities and challenges of IDT to support it.

\section{Table I here}

\subsection{Data collection}

Data for this research are collected via different sources including interviews, documentations, archival records, direct and participants' observations and focus group meetings. A database is created and all the data for the cases are stored in it following Miles et al. (2013) and Stake (2013) guidelines.

\subsubsection{Interviews}

Interviews with companies are conducted with the informant person(s), in each company, with appropriate knowledge of omni-channel systems and the IDTs used for managing product and data flows through them. Given that this research focuses on data management and integration aspects of the omni-channel system (including their technical and inter-organizational issues), the interviewees 
are introduced by their companies as the most informed and experienced people, who are involved in decision making processes regarding design and setting of the omni-channels and implementing the IDTs (from both the IDT user and IDT provider companies). The interviewees are also knowledgeable about all the issues which their different departments are coping with in products and data flow management in their omni-channels. Prior to conducting the interviews, the list of questions is sent to the interviewees in a timely manner, to enable them to receive any required complementary information from other departments in their companies if needed.

The interviews are in a semi-structured format, and each took 60-90 minutes. All the interviews are recorded and transcribed according to the guidelines by Yin (2014). The interviews are done face-toface, via telephone and via email (as shown on Table I) - which are the established mediums of conducting interviews in qualitative studies (Bryman and Bell, 2007). A group of the interviews are conducted via telephone, due to its suitability to the respondents (e.g. when they work from home, or they are on business trips). The literature shows no significant difference between validity and reliability of face-to-face and telephone interviews (Sturges and Hanrahan, 2004). Even there are studies encouraging using telephone interviews more often in qualitative research (e.g. Novick, 2008) by emphasizing its advantages over face-to-face interview - including reducing the costs of research, being easier to administrate, and eliminating the effects of characteristics of the interviewer (e.g. class or ethnicity) on the interviewee (Bryman and Bell, 2007). To ensure the validity and reliability of telephone interviews, Bryman and Bell's (2007: p.216) measures are adopted, including: interviewing targeted respondents, selected thoughtfully (not randomly) in each company; and asking the interviewees to email supporting documents which provide more information about the topics discussed during the interviews, to address limitations in illustrating visuals or figures by the respondent during the telephone interviews.

Two respondents have requested to answer the interview questions via email (by filling the interview form), to make sure they have enough time to search and provide accurate answers to all questions, and to make internal enquiries with their colleagues. After receiving their responses, follow up emails are exchanged, if required, to ensure understanding the answers clearly by the researchers. Email interviews have a few advantages over face-to-face interviews, including providing more details in written answers, providing a cleaner text, and eliminating the effect of developing personal relationships with the interviewees, which can affect the research (Bryman and Bell, 2007: p.674; Murray and Sixsmith, 1998, p:118). Following Bryman and Bell (2007) and Murray and Sixsmith (1998) guidelines for validity and reliability of email interviews, prior agreements are made with the respondents for the email interview; detailed and structured records of the questions and answers and their time and date are documented; and all the answers are stored in the case studies' database.

The interview questions aim at creating an in-depth understanding of the operations of the companies, the agents, and channels in their omni-channel systems, and the information systems (including IDTs) used for managing their intra- and inter-organizational operations. The questions also address IDT applications and implementation issues around them. The list of interview questions is available in Appendix 2a. The interviews transcripts are then coded by using NVivo, leading to an appropriate and detailed analysis of the qualitative data.

There have been very few cases of contradicting remarks stated by the interviewees (for example, on the choice of right track and trace technology for product identification, considering the cost and accuracy tradeoffs). In those cases, following the recommendations by Power (2004), listening to the 
'logic of practice' of the interviewees, and triangulation of data (e.g. by discussing these issues in the focus groups and by reviewing documents of the studied companies) have been used to maintain validity of the findings. The approach used for coping with divergent views and information provided by interviewees from the same company (Watson, 2006; Power, 2004), is sending follow up emails to the respondents who have provided those different views, by copying all of them on the email, and asking them to clarify the ambiguity and contradiction in their answers. These follow up emails are very useful, by leading to either coming to a consensus on the provided insights, or identifying different scenarios, i.e. solutions depending on the use case. For example, using specific IDT can depend on the type of product, its value, or the physical condition in which the product goes through in its channel, which might be a reason for providing divergent answers by the respondents. When identifying divergent views from different sources of data from the same company (e.g. interviews and documents), data triangulation (Yin, 2014) is used by sending follow up emails to different respondents from the company and asking for clarifications on those topics. These investigations lead to revising some of the propositions of the study.

Key information about the company interviews and further details of them are provided in Table I and Table II respectively.

Table II here

Interviews with consumers, of the case companies, are conducted in semi-structured format (Flick, 2009) to explore omni-channel data flow integration and the relevant IDT applications from the consumer's point of view. The interviewees are the consumers of companies 3 and 8-14 (listed in Table I). The initial consumers sample frame is recommended by the companies or extracted from the companies' databases of consumers, who have given the consent to be contacted for marketing and research purposes. Out of 126 consumers of the sample frame, 52 responds to the initial contacts and finally 38 interviews are conducted completely. The interviewees represent the case companies very well (3-6 interviewees from each company), with a diverse age, income and education range, with experience of buying products through omni-channels (i.e. online and click-and-collect, besides in-store shopping). During the interview, verbal explanations are provided to the interviewees about the structure of the omni-channels and the agents who are involved in them. Explanations and examples are also provided about the types and flows of data, that are collected from/provided by the consumers. The interviewees' answers are not limited to one specific company or omni-channel, and largely reflect their knowledge of and views to omni-channel and its relevant data flows.

The interviews, with the companies and the consumers, are very valuable for this research, as they lead to gaining a deep understanding with explanations about omni-channel data types, data flows, and the IDT applications for data capturing, sharing, and analysis throughout the omni-channel system, from both consumer and business perspectives. These explanations where not achievable via any other source of case study evidence. 


\subsubsection{Documentations}

Different types of documentation, including information available on the websites of the companies, articles and white papers about the studied companies and their omni-channel systems, and their archival records and annual reports are collected (Stake, 2013; Yin, 2014) for this research to complete the evidence gathered via the interviews. Other important sources of information are the videos available about the operations of the companies and the way the IDT enhances its relevant omni-channel operations. Documents are very important sources of data in this research, because full understanding of the omni-channel structures, and more importantly the architecture and structure of the IDTs (e.g. the connections between different elements of their systems such as auto-identification devices, data capturing, data exchange and data storage in within- and inter-organizational levels) are possible only via studying the documents provided by the companies. Considering the explorative nature of this research, the technical information provided in the documents (e.g. technical figures and maps of the systems showing the interconnections of the IDTs and data flows), is essential in the research to help formulating the findings of the study. Moreover, the documentations enabled the validation through triangulation of the case studies' data (Yin, 2014). The documentation collected from the companies and their details are presented in Table II.

\subsubsection{Observations}

Visiting five sites of the studied companies, and observing their IDT-based solutions at work and demos of the advanced systems that they design to utilize, help developing the insights of the researchers, by providing an understanding of the practical aspects of implementing the systems, and the technical considerations and limitations related to them. Pictures are taken and videos of the IDTs of the companies are recorded (subject to receiving prior consent from the companies). Furthermore, notes are taken by the researchers during the visits. During and after making direct and participant observations, new questions are raised by the researchers which are answered by the companies' representatives, leading to improving the quality of findings of the paper and increasing the level of their practical relevance. The site observations are complementary sources of data as they provided new insights into the IDTs which are not possible to be achieved with other data sources. Through the site visits, the way data is generated or shared by using IDT are demonstrated by the companies.

Observations are used for triangulation and validation of the case study data (Stake, 2013; Yin, 2014). Details about the participants and direct observations are provided in Table II.

\subsubsection{Focus groups}

Four focus group meetings with participants from the IDT provider companies (companies 15-17 shown in Table I) and the researchers take place for the purpose of improving the understandings of the researchers and validating and triangulating the findings of the study (Eisenhardt, 1989; Yin, 2014). The meetings occur in different stages, in order to provide required insights and feedback from IDTs experts' perspective which guide the researchers through the entire research process, and ensure rigor and robustness of the findings. The first and second meetings take place in initial stage of the study, when the researchers present the scope of the research and the managers provide important insights regarding inter-organizational data management in omni-channels and the IDTs which are used for 
organizing the data flows. Also, the discussions in the first two meetings help identifying suitable sectors and companies for the research. In the third meeting, the findings generated from analyzing the interviews and documents of companies 1-14 are presented to the managers, and feedback and additional technical details are provided by them on the IDTs used by those companies (companies 114) and the opportunities and limitations related to implementing them. In the fourth focus group meeting, which takes place at the end of the study, the findings and initial propositions of the research are presented for the managers and feedback is received from them. The focus group meetings take place face-to-face.

Several important insights in relation to inter-organizational aspects of data management (e.g. issues related to compatibility of databases of companies) are identified through these meetings which contributes to the findings of the study. The researchers moderate the meeting by providing a clear agenda for the conversations. They record the conversations and the highlights of the discussions. After each meeting, the researchers meet to identify the main themes of conversation and to discuss the points of group consensus (Kitzinger, 1995). Details about the focus groups and their participants are provided in Table II.

\subsection{Data analysis}

For analyzing the case study data, after collecting the evidence, the transcripts are coded and analyzed using NVivo. The keywords used for data analysis include: 'provided data', 'gathered data', 'data management', 'integration' and 'information and digital technology'. Matrix displays are used within spreadsheets displaying the codes on one dimension and quotes on the other (Kaufmann and Denk, 2011; Miles et al., 2013). This analysis procedure leads to identifying robust patterns within case studies (Eisenhardt and Graebner, 2007). Via eight brainstorming sessions between the researchers, the patterns identified through the case study analysis process are refined, leading to 'sharpening' the propositions of the study (Kaufmann and Denk, 2011; Yin, 2014).

Differences in business models of the companies (e.g. having different roles or providing their products via different channels) and their system setups (e.g. using different types of IDTs and sharing data at different levels with different types of companies) are taken into account when the data are analyzed. Following the guidelines on cross-case analysis by Stake (2013), the research questions are used as a guide, when applying the findings of each case for creating the overall findings of the research. Crosscase analysis enables more generalizability of the research findings by identifying the relevance of applicability of the findings to other settings (Miles and Huberman, 2013: p.173). Considering the research aim in exploring omni-channel data flows/integrations using IDTs from consumer and business perspectives, differences in business models and setups of the case companies of this research lead to providing more generalizable results. However, at the same time, identifying the similarities and differences between business models and system setups of the studied cases demands significant amount of synthesis by the researchers, to keep the focus on the areas of their businesses and IDTs which can provide answers to the research questions. The sampling frame of the study and unit of analysis (explained in sub-Section 3.1) are used as guides in this process.

In the Findings section, following the guidelines of Pratt (2009), the research outcomes are organized in sub-Sections 4.1-4.3, supported by the power quotes, which are presented in Table III. 


\subsection{Quality of research}

Steps taken during the data collection process, to ensure robustness, validity and reliability of the research have been explained in each sub-section related to every source of data (sub-Sections 3.2.13.2.4).

Following the recommendations by Yin (2014), four widely used tests, including construct validity, internal validity, external validity, and reliability have been applied to ensure rigor of this case study research (Gibbert, et al., 2008). Table IV shows the tactics through which these tests are used for this research and the stages of the research in which the tactics are implemented.

Table IV here

\section{Findings}

The outcomes of the qualitative data analysis of this research indicate various channels of generating, capturing, receiving, sharing, and analyzing data throughout the omni-channel system, which can be viewed from the perspective of, first, the consumer and, second, the business/retailer - as presented in sub-Sections 4.1 and 4.2 respectively. The data, exchanged in the consumer and business sides are then explored further in terms of their types and the technologies, used to capture, share and analyze them in sub-Section 4.3. In each sub-section the research outcomes are summarized in the form of notions.

\subsection{Data flows: consumer perspective}

Consumer-side omni-channel data flows are organized around the consumer shopping journey, widely known in the business research as a sequence of touchpoints or a process that a consumer follows to acquire and use a product (Følstad and Kvale, 2018; Harris et al., 2021). Reference textbooks such as Blackwell et al. (2011) recommend five steps of "need recognition", "information search", "evaluation", "purchase", and "post-purchase evaluation" for the consumer buying journey, and Harvard Business Review analyzes it based on "consider", "evaluate" and "buy" steps (Edelman, 2015). The recent marketing literature simplifies it in "pre-purchase", "purchase", and "post-purchase" stages (Grewal and Roggeveen, 2020; Lemon and Verhoef, 2016; Tueanrat et al., 2021), and omni-channel retailing research establishes the shopping journey in pre-purchase, payment, delivery, and return steps (Saghiri et al., 2017). Further synthesis of the consumer shopping journey is provided in Figure 1a, where different steps, identified by the literature, are mapped and the features of different consumer shopping journey classifications are underlined. 
Taking these classifications into consideration, analysis of the collected data of this research has come up with the following themes (organized as the main steps) of the consumer's shopping journey:

- "searching for product", "seeing the product", "trying the product", "touching the product", "consumers' review/feedback" $\rightarrow$ outlined as C1. Pre-Purchase: collecting product data

- "payment", "purchase terms" $\rightarrow$ outlined as C2. Purchase: selecting/buying the product

- "home delivery", "collection point", "delivery updates/status" $\rightarrow$ outlined as C3. Receiving and Using the Product

- "returns", "reverse logistics", "home collection", "drop-off point" $\rightarrow$ outlined as C4. Aftersales Service, including possible returns

C1-C4 form the center column of Figure 2a, and help organizing the consumer shopping journey data flows chronologically. They reflect the consumer journey from the time he/she might find about the need for the product and start thinking/searching for it, up to the point he/she receives it, and even after that, when (if) he/she decides to return the product.

Various channels that provide/collect data to/from the consumer are respectively presented on the lefthand and right-hand side headers of Figure 2a. Details of data flows at each step of the consumer journey are provided in the main body of Figure 2a, and their details are explained in sub-Sections 4.1.1- 4.1.4. The code in each box in Figure 2a reflects the grouping, done in the initial analysis of the case studies and interviews (e.g. CI1: Consumer Input data, relevant to consumer journey step 1 - pre-purchase). The relevant IDTs to each data flow are also specified by bold capital letters in each box (e.g. B: Barcode; D: Data Analytics). The explanations of each data transaction, in the following sub-Sections, are supported by short power quotes, as described in sub-Section 3.3 and fully listed in Table III.

\section{Figure 2 here}

\subsubsection{Pre-purchase: collecting product data (C1)}

In the pre-purchase step, the consumer tries to learn about the product or expand his/her knowledge about it; hence he/she may need all or some of the following data.

Product data including specifications, material/ingredients, functions and features are typically available from various sources including store and non-store channels (CI1.1). Various sales channels help the consumer not only to receive the product data from the physical store, but also from the store's website, other e-tailers, catalogues or tele-sales, pop-up stores, and even the manufacturer itself, as the original source of product core data:

"... click on the link in the ad [shared in social media] takes me directly to the online store, where I can find full product data." (Consumer 6)

The retail store has been conventionally the right place to view and try the product, and physically compare it with other available options there (CI1.2). Advanced technologies such as augmented reality have made viewing and trying the products (at least some products) more viable via online and virtual channels: 
"I go to the store to see the product physically and eventually try it on ..." (Consumer 1)

"Augmented reality [available online] is... the closest to physically trying the products. (Consumer 3)

Therefore, box CI1.2 in Figure 2a is extended beyond the physical retail store.

In addition to the product description and features, product review reports, prepared by the sellers or third-parties (CI1.3), can support the consumer's purchasing decision. Product data can be also acquired from other consumers, which are shared via social media, product review services, and the sellers' websites. Even though they are not typically well organized and standardized, other consumers' reviews and comments provide some good insights on the product, which are not easily available in formal reports:

“... other consumers' reviews [shared online are] affecting my choice.” (Consumer 4)

The consumer purchase decision can be affected by the available stock level (CI1.4) as well as price and promotion (CI1.5). For some products, a reduced price, marketing promotion, or low stock availability may be good motivations for consumers to buy more and/or faster:

“[social media] influencers .... are affecting my decision to buy ...”. (Consumer 5)

“... multi-brand websites offer great discounts and more product stock variety.” (Consumer 7)

“Instagram adverts ... suggest me products that I am looking for." (Consumer 8)

The consumer, in the pre-purchase step, usually has questions about the products, purchase terms, delivery options, and the like. These queries have been conventionally shared with the seller. But omnichannel retailing makes it possible for the consumer to approach non-sales channels and social media, and share his/her questions there (CO1.1).

"I can find answers to my questions about the product from the seller, in specialist websites or even from you-tube" (Consumer 21)

The consumer queries can then form a valuable knowledge-base for sellers, market analysis service and manufacturer, which indicates what consumers are looking for, and what their main concerns are. These can inform those channels to work on their input data in the future, and make the answers available for any potential questions around them.

Channels that are involved in the pre-purchase step can monitor the consumer's shopping behavior and record its moves and preferences (CO1.2). These data can be analyzed further and form a basis for future omni-channel market intelligence.

"I am surprised that companies have so much information about me." (Consumer 9)

The data provided through CI1.1-CI1.5 are dynamic and might be inter-dependent too (e.g. stock availability in CI1.4 may affect the pricing and promotion CI1.5). To adapt to those changes and ensure an adequate, ideally real-time, synchronization among CI1.1-CI1.5, all data-providing agents (sales, non-sales, and social media - in the left-hand side header in Figure 2a) need to have a good visibility of the data they generate and share. This visibility can be driven or instructed by a leading or influencing 
agent - for example a manufacturer can instruct the retailers and other sales channels to use its original product data format. Moreover, the self-organization property of the data-providing agents, as expected from CAS agents, enables them to establish good connections with each other. The connections are not expected to be identical. For example, while store and online channels of one retail brand can benefit from the product, stock availability and price data sharing by integrating their databases, a similar data sharing among a retail store, manufacturer, and an independent online retailer may happen via different agreements between every two agents (e.g. sharing the point-of-sales data by the store with the manufacturer at the end of each day), or through data monitoring and tracking schemes, run by each agent (e.g. online retailer). Anyhow, due to the importance of consistency in and data generation and sharing (in any form that the omni-channel agents agree on), it should be done through formal mechanisms to assure the proper commitment of all relevant parties.

Similar to the data-providing side, data-gathering agents (the right-hand side header in Figure 2a) may track and collect consumer enquiries or shopping behavior data and share them with each other through mutual agreements. This self-organizing intelligence of the consumer behavior, preferences, and queries, at the agent level (extended across multiple channels in CO1.1-CO1.2), provides a high visibility of the market at the omni-channel system level, as a CAS. The thorough visibility and integration of the data-providing/gathering agents as well as their self-organizing ability to capture, generate and share the product data at the pre-purchase stage (of the consumer shopping journey) fundamentally differentiate the omni-channel system from single or multi-channel systems - which do not intend or are not capable of managing such an exhaustive level of data flow integration. In summary:

Notion 1: At the consumer journey's "pre-purchase" stage

(1a) data flow integration among the self-organizing data-providing/gathering agents supports the omni-channel system adaptability - as a CAS.

(1b) data flow integration instructed by one leading agent or mutually agreed on by a group of agents should go through formal mechanisms which need contractual governance.

\subsubsection{Purchase: selecting and buying the product (C2)}

In the purchase step, the consumer decides about the specific product that he/she wants to buy, where he/she wants to buy from (i.e. sales channel) and how he/she is going to receive it (i.e. delivery options). During the purchase and payment process, the consumer may receive more data, and the sales channels also gather some data from $\mathrm{him} / \mathrm{her}$, as follows.

To finalize his/her decision, the consumer needs to understand and agree the terms and conditions (T\&Cs) of the sale (CI2.1). In practice, not many consumers are interested in reading the whole T\&Cs in full, but usually some key points such as delivery/collection date, warrantee/guarantee, and return policy are reviewed in detail.

"I never read the terms and conditions. I just check the box with the agreement." (Consumer 10)

"Often I save the terms and conditions on my desktop, but then I delete them after a while without reading them." (Consumer 11)

Therefore, the sales T\&Cs should be available in various formats. It is notable that although these data are mainly needed during the purchase step, and should be agreed on before payment, they should also 
be available for the foreseeable future, in case the consumer wants to go back and review them later. When the payment is done, the consumer should receive a full record of his/her purchase, payment confirmation, and a tracking code to trace the order (CI2.2). This data is generated, stored, and shared at different levels of details and in different format, as investigated through documentation and archival records in this research.

Once the purchase is done, the consumer information $(\mathrm{CO} 2.1)$ is passed to a number of channels to prepare the order for him/her. As the observation in all case companies (with sales facility) of this research reveals, depending on the product and terms of purchase, these data may go beyond the name and address, and can be a good source of intelligence for future sales, market research services, manufacturers, and product and service development teams. During the purchase process, the sales channels, physical or virtual, observe, capture, and record the consumer's buying behavior (CO2.2) for example preferences toward promoted items, coupling a product with another one, group purchase of multiple sizes or colors, or preferences toward a particular mode of payment or delivery.

"I would prefer that one [i.e. PayPal], rather than putting my entire credit card details" (Consumer 12).

These data are of high value for future sales and the logistics services around them. CO2.3 keeps the payment data and shares them with relevant agents, if the consumer agrees, for future use.

Adaptability of the omni-channel system in this step should meet variations and alterations in the sales and delivery T\&Cs, consumer/payment details, and payment methods - while considering their wider operational and logistical implications. Payment methods (credit/debit card or cash) can shape the omnichannel structure and the logistics around it. For example, the click \& collect model will be in the form of buy-online-collect-from-store for consumers who pay by card, and in the form of reserve-online-payin-store for cash payers, each has operational implications for the omni-channel system (e.g. in stock management), and should be regulated and communicated among the relevant agents properly. Similarly, any extended warranty, promised by the retailer to the consumer, should be formally communicated and shared with the manufacturer to put proper plans and resources in place for them.

Such an overarching view to the payment stage in omni-channel retailing, is not essentially comparable with store-only or multi-channel retailing models, where their payment processes are handled entirely separated. Therefore, it can be stated that:

Notion 2: At the consumer journey's "purchase" stage

(2a) payment and purchase choices affect (may change) the omni-channel arrangements and processes, where data flow integration among the relevant agents supports the omni-channel adaptability to those changes.

(2b) omni-channel adaptability to change needs formal (contractual) governance to instruct all relevant agents of the omni-channel about the sales/purchase T\&Cs and their responsibilities against the T\&Cs.

\subsubsection{Receiving and using the product $(\mathrm{C} 3)$}

In this step, the product is handed to the consumer (e.g. in the store or at a collection point) or delivered to the address specified by the consumer. Although it is the logistics service that is largely involved in 
this step, there are many other agents of the omni-channel system which contribute to providing, gathering, and analyzing the input/output data of this step, as explained below.

After placing the order, the consumer needs to know when the product is to be delivered or is ready for collection (CI3.1). Since there are different parties and channels involved in product delivery, it is the omni-channel responsibility (as one unit) to communicate the delivery status to the consumer. Omnichannels have experienced many examples of consumer perplexity, i.e. when he/she buys the product from company $\mathrm{X}$, then receives a shipment update from logistics service $\mathrm{Y}$, and a "ready for collection" message from collection point $Z$, separately and quite confusingly.

"it is really confusing when I receive a text about my delivery from a so-called logistics company, ... it is confusing as it is not clear which order it refers to as I may have purchased different things from different retailers. I simply need only the company, I bought the item from, to contact me [about any delivery update] ..." (Consumer 22)

Observing and reviewing the sales and logistics activities of this research cases prove similar procedures and data transactions in them. When the product is delivered/collected, the consumer should be informed via a product delivery confirmation (CI3.2). This is particularly important when the buyer is not the same person as the recipient of the product (e.g. if the item is sent as a gift to another person). Besides, attached to the product are the user guidelines (CI3.3) - in the form of booklets, e-manuals or even videos in the social media, shared by sales or non-sales sources, or by other consumers.

Product delivery should be confirmed by a signature, or a photo of the consumer while he/she is receiving the product, as an approval and evidence, which the delivery service can then present to the sellers or can be recorded, in case any dispute arises on delivery later (CO3.1). Consumer experience and feedback (CO3.2) are then collected through various channels to maximize the feedback rate and collect further details.

"I answer the quick and easy ones [(i.e. consumer review/feedback questions] but ignore the time-taking surveys." (Consumer 13)

Product delivery to a wide range of locations (e.g. home, store, and collection point), and its flexibility in responding to the consumer's heterogenous and changing choices/instructions indicate the omnichannel adaptability. Product delivery operators need to be kept updated about the latest status of the consumer order and delivery address or special request, which needs sales-delivery channels integration - through formal platforms and arrangements around them.

Such extended and integrated inter-connections in the omni-channel product delivery, are not traceable in bricks-and-mortar or multi-channel retailing - as the former do not expect many interconnections, and the latter cannot handle them. In view of that:

Notion 3: At the consumer journey's "receiving" stage

(3a) integration of the delivery operations to other relevant stages and agents of the omni-channel system is crucial for its adaptability against changes in the delivery requirements and conditions.

(3b) omni-channel adaptability to change needs formal (contractual) governance to instruct all relevant agents about their responsibility against sharing the delivery data - to facilitate a proper response to its change(s). 


\subsubsection{Aftersales services, including possible returns (C4)}

For aftersales services (CI4.1), such as a warranty/guarantee, the consumer may deal with the retailer, manufacturer or third-party service companies. Regardless of which specific company takes care of this service, the consumer expects a consistent service from the omni-channel system as a whole. In case a consumer decides to return a product, he/she needs full return instructions (CI4.2), including the return address, label, code, and so on. These should be provided by the retailer, or the return service which specifically handles the reverse logistics part of the business. An electronic or physical receipt, including a confirmation or tracing code would assure the consumer that the returned product is taken care of, and the refund/exchange will be done according to the terms of the purchase (CI4.3).

“... different online retailers have different return terms and conditions and I do not have time to review all of them..... I prefer to buy from only one retailer ... I know their terms and conditions." (Consumer 14)

"...If a company gives vouchers for returned items or if I should pay for posting the product back then I don't buy from them ..." (Consumer 15)

As a common practice, observed by this research in the logistics and sales case studies, when the consumer returns the item, he/she should be sure to attach the return label, including the return barcode and address (usually provided by the return service), to the returned product (CO4.1). This helps the return service to handle the product and the refund quickly and correctly.

To receive the refund, the consumer might need to re-confirm his/her payment card information (CO4.2), if it has not been originally in cash. In some cases, the refund is not made directly, but via vouchers or coupons.

To offer the after-sales operations smoothly, the associated agents need to coordinate and respond to the changing requirements of the product returns or warranty in a timely manner. The associated data flow integration, which requires the related agents' obligations, can close the adaptability loop of the omni-channel, as a CAS, at this stage, which accompany and support the consumer throughout his/her shopping journey - the advantage which store-only, online pure-play, or even-multi channel retailers lack.

Notion 4: At the consumer journey's "aftersales" stage

(4a) aftersales service providers should be fully aware of the product, product data, delivery conditions and sales T\&Cs, hence they need to be integrated to the rest of the omni-channel data system, to adapt to the consumer needs.

(4b) expansion of data flow integration up to the aftersales stage needs formal commitment (contractual governance) of all earlier stages of the omni-channel and its relevant agents, as well as the aftersales service providers to share the product, delivery, sales, aftersales, and return data.

\subsection{Data flows: retail/business perspective}

The omni-channel data flows in the retail/business side are organized around the main actions of the retailer in managing and responding to the market. Croxton's (2003) model organizes the retail operations, in a more conventional environment, through market review, defining and planning order 
fulfillment, and logistics network evaluation sub-processes. Moving toward online-offline retail environments, Leung et al. (2018) recommend a B2C e-commerce setting based on key steps of launching sales platforms, receiving orders, internal order processing, and outbound delivery. Zhang et al. (2019) devise the retail's online fulfillment in: (a) core order receipt, pick and pack, and shipment stages, and (b) supportive inventory management, warehousing logistics, and delivery and after-sales operations, to secure the product availability and demand fulfillment. Similarly, Zhu et al. (2021) divide online order fulfillment into two parts: online operations (including market analysis and order processing) and offline operations (including stock management, picking, packing, and delivery). Further synthesis of the retailer's activities is provided in Figure 2b, where different steps, identified by the literature, are mapped and matched against each other. In summary, the retail order fulfillment settings, recommended by the literature, can be organized in decisions and activities around market, demand, orders, product availability, picking and preparing items for each order, delivery, and aftersales. These are consistent with the retailer's actions, extracted from the collected data of this research including:

- "having an understanding of customers", "learning about consumers' needs", "understanding the market through analysis of social media data" $\rightarrow$ outlined as R1. Market/Demand Analysis

- "pulling demand and supply capacity data together", "monitoring inventory availability", "logistics capacity" $\rightarrow$ outlined as R2. Securing Product Availability

- "product delivery", "home delivery", "click and collect" $\rightarrow$ outlined as R3. Demand Fulfillment

- "returns", "reverse logistics", "home collection", "drop-off point" $\rightarrow$ outlined as $\mathbf{R 4 .}$ Aftersales

R1-R4, forming the center column of Figure $2 b$, cover a broad range of activities that a business/retail should undertake to meet the consumer demand. These start from understanding and analysis of the market and move toward product delivery (order fulfillment). They also go further and include aftersales activities, mainly around gathering consumer feedback and handling returns.

Figure $2 \mathrm{~b}$ header row shows the various channels, on the left-hand side, that provide data, and on the right-hand side, that collect data, to and from the retailer respectively. Details of the retailer data flows within each channel are provided in the main body of Figure $2 b$, and explained in sub-Sections 4.2.14.2.4. The code in each box (in Figure $2 b$ ) reflects the grouping, conducted in the initial analysis of the case studies and interviews (e.g. RI1: Retailer Input data, relevant to retailer step 1 - market/demand analysis). The relevant IDT to each data flow is also determined by bold capital letters in each box (e.g. B: Barcode; D: Data Analytics). The explanations of each data transaction, in the following subsections, are also supported by short power quotes, as described in sub-Section 3.3 and fully listed in Table III.

\subsubsection{Market/demand analysis (R1)}

To manage its capacity, replenishment, inventory, and delivery plans, the retailer needs to have a good knowledge of the market and consumer demands, which are typically acquired from the market intelligence services (RI1.1) and/or directly from the consumer/market (RI1.2). At the same time, the 
retailer constantly analyzes the market, behavior, demand trends, and retail technologies. The outcomes of those analyses can be accessible by consumers (RO1.1) and market analysis services (RO1.2).

“... deep understanding of customers and market is a part of the success of omni-channel retailing." (Company 13)

"Analyzing data on Facebook and Twitter is one way of understanding the market ..." (Company 13)

A diverse range of market data/intelligence sources, if shared/connected rigorously in the omni-channel system, significantly support its individual agents to adjust or even restructure their processes and resources (e.g. warehouse relocation). Hence, they make the whole omni-channel system more adaptable to the market uncertainties and fluctuations - compared to single or multi-channel retailers which are quite disadvantaged in this area. In view of that:

Notion 5: At the business "market/demand analysis" stage

(5a) to adapt to changes, omni-channel needs rigorous demand market data flow integration, contributed to by all relevant agents.

(5b) The rigor of the market/demand data can be assured through formal data capturing and sharing mandates (i.e. contractual governance).

\subsubsection{Securing product availability (dealing with supply side - R2)}

Based on its collective knowledge of demand (i.e. consumer confirmed order and forecasted demand RI2.1), the retailer plans to fulfill the demand for its products on a regular basis.

“... they manage to pull together overviews of demand data ... from across different silos and Excel spreadsheets"(Company 10)

In addition to the estimated demand size, the retailer should have a good visibility of stock availability with the manufacturer and wholesaler/distribution center (i.e. those who are required to replenish the retailer's order), as shown by RI2.3 in Figure 2b. Depending on the number of suppliers, managing such data is important for retailers. In some of the studied companies, data exchange on ordering and product availability is done using a more integrated format, e.g. electronic data exchange (EDI) systems.

“... replenishment is carried out through a B2B platform where ... inventory availability [is visible]" (Company 11)

“... retailers are putting pressure on suppliers to take more responsibility for a master data set-up [with full visibility of stocks/orders] " (Company 1)

Moreover, the product's logistics considerations and requirements (RI2.2), such as special storage temperature, may affect the time and condition of receiving the product, and the retailer should know about them in advance. These conditions and requirements can also be dictated by the retailer, as observed in a number of case studies of this research (i.e. RO2.1).

"Having correct handling information will lead to better movement of products ..." (Company 8) 
When the order is placed by the retailer (RO2.2.), the retailer expects to receive an advanced shipment notice (ASN) from the dispatch point (RI2.4). ASN greatly helps the retailer to manage its product receiving, storage, and delivery plans and operation. To receive its orders, the retailer expects to have the latest status of the product shipment, until it arrives (RI2.5). Those updates can be provided by the shipment origin (i.e. manufacturer and wholesaler/distribution center) or the logistics service provider.

"... there are process checks ... to ensure that the right information is going to the customer at the right time ... ASN is a process that we are looking at ..."

"[after the order is placed] products go into a black hole until when they are ready to ship." (Company 11)

If the product is supposed to be shipped to the consumer's address or collection point, then the delivery status is to be shared with the consumer (RO2.3). Upon receiving the product, the retailer should check the product and confirm the delivery to the relevant parties. Any problem with the product or delivery is shared with those parties too (RO2.4).

"[Delivery services] use an Access database from the warehouse to manage online orders" (Company 10)

"In track and trace [system] Logistics is working with the purchasing team much more closely on managing logistics data." (Company 11)

Finally, payment is made (RO2.5), according to the invoice (RI2.6).

"End to end integrated system [including point-of-sales and invoicing] will allow real time view of stock." (Company 10)

In this step, whereas RI2.1 contributes to the demand/market intelligence (added upon RI1.1 and RI1.2), RI2.2-RI2-6 provide omni-channel retailing with supply market intelligence and supply status, necessary for agents to adjust or restructure their processes and resources (e.g. stock tracking and stock availability) - which make the whole system more adaptable to supply uncertainties and fluctuations. $\mathrm{RI} 2 \mathrm{~s}$ and $\mathrm{RO} 2 \mathrm{~s}$ data at this stage are typically shared to/by the retailer via formal procedures (e.g. ASN and payment methods), that all relevant agents should follow.

Notion 6: At the business "securing product availability" stage

(6a) to adapt to changes in the supply side, omni-channel needs rigorous supply market data flow integration, contributed to by all relevant agents.

(6b) The rigor of the supply data can be assured through formal data capturing and sharing mandates (i.e. contractual governance).

\subsubsection{Demand fulfillment (dealing with the consumer side) and aftersales (R3\&R4)}

Most parts of these steps include data interchanges with the consumer, as already addressed in subSection 4.1. But, to deal with the consumer, the retailer should work with other agents of the omnichannel system too. Technical advice about the product, any required update or change in it, or callbacks should be originated by the manufacturer (RI4.1). The retailer should also pass the required aftersales services, raised by the consumer (e.g. any technical or functional problem or difficulty in the product 
usage) to the manufacturer (RO4.1). General consumer feedback is also shared with other relevant parties (RO4.2).

In the case of a product return, the return instructions should be provided by the relevant parties (RI4.2) and once it is returned, its related data should be shared with those parties too (RO4.3). The retailer does not need to be involved in all steps of the return process, but it can be the interface with the consumer to manage the consistent sales and aftersales services of the omni-channel with the consumer.

"Returns is a huge challenge in omni-channel retail. ... no [poor] visibility about returns leads to lack of control on our costs." (Company 9)

“... don't have visibility of returns until [they] turn up at the warehouse." (Company 11)

As addressed earlier in the consumer side (Section 4.1), retailers (as the main interface with consumers) and other omni-channel agents seek a high visibility of the consumer's order and preferences. This may include data flow integration or spontaneous tracking/searching for data via well-established mechanisms, which make the omni-channel order fulfillment and aftersales services more adaptable.

This advanced capability of omni-channel systems, in managing the order fulfillment process seamlessly, cannot be found in single/multi-channel retailers, which are mainly limited to a single/separate data flow(s).

Notion 7: At the business "demand fulfilment" and "aftersales" stages

(7a) to adapt to the product suppliers' and service providers' changes, the omni-channel retailer needs supply/service data flow integration to assure the visibility of the latest status of order fulfilment and aftersales service.

(7b) supply/service data flow integration needs formal mechanisms (i.e. contractual governance) to instruct the relevant agents in sharing the order fulfilment and aftersales data.

\subsection{Omni-channel data types and IDTs}

To be well-systemized, the omni-channel data flows, explained above, need a more focused analysis to apprehend the omni-channel data types and the technologies, employed to capture, share and analyze those data. Further synthesis of the research outcomes has grouped the omni-channel system data into five categories of product data, consumer data, business unit data, sales/delivery/return data and planning data. Details of each data category and their supportive technologies are explained as follows - each section is supported by a summary power quote(s) - which are fully listed in detail in Table III.

\subsubsection{Product data}

An extensive range of data fields can be considered for the product, whose contents can be fixed/static (e.g. product name, size, and ingredient) or variable/dynamic (e.g. product freshness, price, or its location in the sales channel).

“... product data changes through different stages of the omni-channel."(Focus Group 3) 
Labeling the product by barcode and/or RFID tags can facilitate storing and capturing the product data. A Global Trade Identification Number (GTIN) is usually generated by the manufacturer and can be encoded in a barcode or RFID tag, to provide a unique identity for the product (GS1, 2015).

“GTIN is fundamental to our scanning processes [and recognizing] individual units, ... cartons, ... [or any moving] product."(Company 9)

Basic barcodes/RFID tags can be enhanced to more advanced smart tags to embed a wider range of dynamic product data, which can be captured by various sensors or data readers across the distribution and sales channels, or even by the consumer's smartphone. In theory, it looks straightforward to keep the same unique data label for the product from the point it is manufactured until it reaches the consumer. In practice, however, intermediary companies may re-label the products to identify and capture them more easily within their own information system - which is not an appropriate solution for the omni-channel integration as a whole.

"Barcodes are placed at point of origin, [but] for other brands ... [we need to] relabel [products] with [a new] SKU number. Hierarchies of scanning from unit to box to pallet to truck [is done by barcode then]" (Company 11)

Among more advanced technologies, augmented reality, as addressed earlier, is becoming prominent, sharing product data more thoroughly and tangibly. This is in line with the literature (Heller et al., 2019) and confirms the practical relevance of new technologies in omni-channels. Besides, the consumer's knowledge of the product is not limited to the data attached to the product. Product reviews and other consumers' comments on the product cannot be put in a structured data format (e.g. barcode), and are typically shared in a text format and world-wide-web (WWW) platforms. Similarly, consumer enquiries about the product are usually in an unstructured, text format, and can be shared via various WWW and extensible markup language (XML) platforms - where XML, for instance, annotates the text in a way to enhance its capturability by both machine and human.

\subsubsection{Consumer data}

Details of the consumer (e.g. name, age, address, and payment information) and his/her order history need to be protected by highly secured data transaction and sharing systems. Data encryption, Payment Card Industry (PCI) compliance, Secure Electronic Transaction (SET), Secure Socket Layer (SSL) technology, and Secure Hypertext Transfer Protocol (S-HTTP) are among the key technologies to be considered by the omni-channel system to protect both the consumer and order. Consumer basic data can be usually gathered and stored in a structured format (e.g. spreadsheet database). However, other data about the consumer, such as shopping behavior, preferences, and comments, are not well-structured in the first place, and need further process and analysis, for example by BDA.

"When collecting consumer data, [we] comply with applicable privacy legislation and regulations, [including] specific guidance on data collection from children."(Company 2)

"We take protecting consumer personal information seriously [using] firewalls, user verification, strong data encryption, and separation of roles, systems \& data ... Systems are proactively monitored through a "detect and respond" information security function" (Company 11) 


\subsubsection{Business unit data}

Key data (e.g. name, address, and products) of all business units involved in an omni-channel system, should be shared among them. Satellite navigation (Sat-Nav) technologies help businesses and consumers to find and plan journeys to each other's location faster, more accurately. Other business unit data such as capacity, performance indicators, and potential capabilities are addressed below in the planning data sub-section. In this category, the key business unit data should be stored and shared in a structured way. Available data standards such as ISO/IEC-6523 (International Organization for Standardization, 1998) or Global Location Number (GLN) can be used to identify the business location.

"[We use] a single Global Location Number (GLN), a code that uniquely identifies member organization, for its entire product range." (Company 1)

"[We participate] in the United Nations' (UN) Blue Number program ... assigns a unique global location number (GLN) to farmers around the world .... gives farmers an online presence,..." (Company 2)

\subsubsection{Planning data}

To assure the product availability for the consumer, and make the product flows smooth, the omnichannel agents need to plan various operations around delivery, inventory, manufacturing, returns, capacity, and so on. Those plans largely depend on consumer orders, market forecasts, market trends and consumer behavior, vehicle delivery capacity, warehouse capacity, human resource policies and regulations, transport infrastructure (e.g. roads) capacity, manufacturing capacities, competitors' plans, demand and capacities, and the like. A more complex situation is where the dynamic data (in addition to static data) are needed, for example inventory status in terms of freshness, or order arrival time based on the latest traffic conditions.

Although quite crucial, these data are neither easily nor widely available. The available data in this category are not always in a structured format. Established systems such as ERP or Warehouse Management System (WMS) can be helpful to generate and share more structured planning data for the omni-channel system.

“... [planning] information exists, but not [integrated and] under one umbrella." (Company 9)

“... we pull together [planning] data ... from different silos/Excel spreadsheets.” (Company 10)

\subsubsection{Sales/delivery/return data}

The process of product delivery needs to be visible for a number of parties, particularly the consumer. This visibility may include accurate product data (both static data such as product specifications, dynamic data such as stock availability); shipment and arrival data, delivery and usage instructions and returns data. 
To this end, RFID technology can share the latest location of the product, from the time when it is allocated to a consumer/order until it is delivered to him/her. Further details can be captured and shared by WSN and CPS. The WSN consists of sensor nodes in the distribution center, local warehouse and stock-keeping points, delivery vehicles, and pick-up points, which means that they can have fixed or moving positions. The sensor nodes go beyond RFID capacities, and measure, compute, and communicate the latest status of the product, order, and location on a real-time basis.

Moving toward robotic systems in product pick-up, packaging, shipment, collection, and even homedelivery, CPS links the delivery status data with the physical equipment of the omni-channel system, and ultimately, integrates the product flows and data flows across the omni-channel system. Using CPS, order and product handling tools and technologies (e.g. operations planning systems and robotic tools) can lead to a smart omni-channel system, whose agents are capable of capturing and sharing data, and handling the product moves autonomously. This applies to the product forward flow, from manufacturer to consumer, as well as the product return flow from consumer to retailer, refurbishment center or manufacturer. At a more detailed level, transport items/equipment (e.g. pallet cases and crates) data can be standardized using the Global Returnable Asset Identifier (GRAI) coding system too (GS1, 2015).

“EDI [is] set up with 3PL to feed data into [their] WMS” (Company 3)

"[We wanted to change our] customer home delivery [service provider] ... but the [existing] Access database can't integrate with [the new delivery service provider]" (Company 10)

\subsubsection{IDT advancement and omni-channel adaptability}

Adapting Ivanov et al. (2020) new insights to Industry 4.0 technologies, IDTs identified above have been found supportive for omni-channel data capturing, sharing and analysis at different scale and pace. For example, where barcode technology is limited to the object's (e.g. individual product or box) static data, smart tag can handle a much higher volume of dynamic data, ERP systems share and analyze enormous amount of that, and BDA deals with big data, defined based on their extremely high volume, velocity and variety. Figure 3 organizes the IDT advancement, based on its volume and speed in capturing, sharing, and analyzing data (shown in $y$ axis), and its application to different data type (shown in $x$ axis). IDTs toward the top part of the diagram are capable of dealing with a higher volume of data at a higher speed. Some IDTs have a limited scope (e.g. GLN applies to the business unit location), and some apply to multiple areas or data types (e.g. BDA).

\section{Figure 3 here}

Looking at the omni-channel's data type and their supporting IDTs, explored above, from the CAS perspective, it becomes evident that more advanced technologies, which can capture, analyze, and share the omni-channel complex and unstructured data, enhance its adaptability. For the frequently changing product and delivery data, extending conventional barcode and RFID to more contemporary smart tags, WWW, XML, CPS, WSN, and augmented reality technologies enables omni-channels to have a realtime visibility of the latest status of the products, their location and availabilities, and also their latest 
market positions (e.g. consumer feedback and rating). Similarly, advanced consumer and business unit data management and analysis IDTs (e.g. PCI, SET and Sat-Nav) can help omni-channel retailing grasp the latest status as well as past/future trend analysis of the supply and demand markets. These can then boost the planning data and their relevant IDTs (e.g. ERP and WMS). For example, a business unit's ERP system, supported by real-time and more accurate product, consumer, supplier, and delivery data, can have more effective autonomous decisions/plans for its production and inventories. The contribution of IDT is not just limited to data capturing and sharing (among IDTs). Advanced IDTs are capable of transferring unstructured data (e.g. consumer behavior) to structured data (i.e. analytics and trends). Moreover, they are competent in comprehending complex data and making autonomous decisions based on them (e.g. smart last-mile delivery system: Schwerdfeger and Boysen, 2020).

The findings also imply that advanced IDTs, due to their technical and administrative complications need more formal procedures for implementations and any integration, made by or among them, requires official arrangements between the associated omni-channel agents. In view of these, it can be stated that

\section{Notion 8:}

(8a) advanced IDTs enhance omni-channel data flow integration by capturing, analyzing, and sharing more complex and unstructured product, consumer, business units, planning and sales/delivery/return data.

$(\boldsymbol{8 b})$ advanced IDTs, to be implemented and integrated in omni-channel systems, need contractual governance of the relevant omni-channel agents.

\section{Further analysis and discussions}

The main findings of this study, in Section 4, have illustrated the scope of data flows in omni-channels from the consumer, business, data type and IDT perspectives. Summing up notions 1a, 2a, 3a, 4a, 5a, $6 \mathrm{a}$, and $7 \mathrm{a}$ and considering individual data flow integration effects, on the omni-channel system adaptability, collectively lead to an inclusive proposition:

Proposition 1: Data flow integration across different agents and business processes of omni-channel system supports omni-channel adaptability.

Notions $1 \mathrm{~b}, 2 \mathrm{~b}, 3 \mathrm{~b}, 4 \mathrm{~b}, 5 \mathrm{~b}, 6 \mathrm{~b}, 7 \mathrm{~b}$, and $8 \mathrm{~b}$ can also sum up the impact of contractual governance on IDTs and omni-channel data flow integration, identified in different parts of omni-channel. Therefore, it can be generalized that:

Proposition 2: Contractual governance of the relationships among omni-channel agents positively contributes to omni-channel data flow integration and IDT applications.

Beyond notions 1-7, further synthesis of the data flow integration of the consumer side and the business side, illustrated in Figures 2a\&b, can be broken down into horizontal, vertical and total integrations (Liao et al., 2017). Horizontal integration refers to communication and compatibility among IT systems of various omni-channel agents. Vertical integration is about connection and synchronization among IT 
devices, tools, platforms and systems at data capturing, sharing and analysis levels (e.g. connecting the equipment sensors at the shop floor level with the control machines in the operations monitoring room, and planning modules of the production management system of the firm). Total integration includes alignment of both horizontal and vertical integration elements across each other, linking and coordinating all relevant devices, business processes and decisions throughout the omni-channel system.

As an example of horizontal and vertical integrations, in CI1.4, on one hand the stock availability data should be shared among the consumer, manufacturer, wholesaler, distribution center, and retailer (horizontal integration); and on the other hand product identification (e.g. barcode and RFID), data capturing devices (e.g. scanners and sensors), data transmission instruments (e.g. WSN), the inventory database, and order fulfillment decisions should be communicating and integrated (vertical integration).

In order to achieve the total integration, the data provider and data collector agents of the omni-channel system (i.e. the header rows of Figure $2 \mathrm{a} \& \mathrm{~b}$ ) should be linked with each other to close the data flows loop - that is the data collected in the right-hand side of Figure $2 \mathrm{a} \& \mathrm{~b}$ need to be processed and fed back to the left-hand side of the figures. This is evidenced by a number of case companies of the current research, where the feedback data are transferred from/to online retailer (addressed in Col 1), physical retailer (addressed in Co14), manufacturer (addressed in Co1,2\&4), wholesalers (addressed in Co5), delivery service (addressed in $\mathrm{Co} 6,7 \& 10$ ), returns (addressed in $\mathrm{Co} 9$ ) and market and social media (addressed in Co13). Figure $4 \mathrm{a} \& \mathrm{~b}$ illustrate the total integration (i.e. feedback loop data flows) by the triangle tables, added on the top of Figure $2 \mathrm{a} \& \mathrm{~b}$. Supporting examples of Figure $4 \mathrm{a} \& \mathrm{~b}$ (borrowed from the case companies mentioned above) show how the collected data in the right-hand side of Figure $2 \mathrm{a} \& \mathrm{~b}$ are processed and analyzed to be fed back to the data providers.

The intended total integration will enable managing omni-channel complexities, at a greater scale and scope - than data capturing, sharing and analysis only in the consumer shopping journey and business order fulfillment process. Data transactions and system synchronizations among the agents can form a strong base for the horizontal and vertical integrations, making omni-channel retailing, at the agent level and as a whole system, more adaptable to internal and external changes and uncertainties. In view of that, it can be stated that

Proposition 3: Omni-channel data flow total integration is achievable through coordination of horizontal integration and vertical integration of relevant devices, business processes and decisions throughout the omni-channel system.

Figure 4 here

It has become evident that the omni-channel vertical integration largely depends on the IDT tools and devices for data definition, identification, capturing, and sharing (e.g. barcodes and RFID to embed data; sensors and scanners to identify and capture data; and CPS and WSN to collect and share the captured data with the data management systems such as WMS or ERP). The omni-channel horizontal integration needs connections among the agents and channels, which is achievable through interconnected and communicating databases and information systems (e.g. ERP). The total integration then 
needs major support from advanced IDTs, such as BDA and IoT. In this regard, IDTs, appropriate for omni-channel total integration, are derived from the case companies of this research as follows:

- Social media is found as the source of big data of the consumers' preference, behavior, and feedback, if analyzed properly with BDA, form a source of knowledge for the omni-channel system. (Company 13)

- Demand data (e.g. demand size, location, and type) are collected from all various sources (e.g. online sales websites, product reviews, retail shops, and delivery services). Shared sales databases and XML/WWW technologies are helpful and should be coupled with advanced analytics to provide a good view of demand. (Company 10)

- Shared databases and XML/WWW platforms among various parties who are involved in the demand fulfillment process (e.g. manufacturer, distribution center, and delivery) assure accurate and timely decisions and actions (e.g. inventory availability) by the omni-channel system. (Company 11)

- Data visibility is expected to be omni-channel-wide, where real-time data are communicated among the relevant entities in an IoT system (e.g. the manufacturer can see the latest status and performance of its products in the retailer or consumer sites (Company 1)

- Product returns/reverse logistics is a valuable source of market data, which contribute to the market intelligence, if recorded and analyzed adequately [using BDA]. (Company 9)

- Consumer/product data, collected by various omni-channel entities, need to be shared by the relevant parties (i.e. emphasizing the role of IoT and shared databases), and analyzed in an advanced level (i.e. emphasizing the role of BDA). (Company 9, 10)

Accordingly, the IDTs required/implemented to achieve total integration are identified and proposed for the triangle tables of Figure $4 \mathrm{a} \& \mathrm{~b}$.

The outcomes of total integration and its supporting IDTs (e.g. BDA) can go beyond the processed data, and in most cases can build a knowledge-base and intelligence for the future decisions and actions of the omni-channel system. Therefore, while the earlier notion $8 \mathrm{a}$ refers to the relationship between IDT and omni-channel data flow integration, further analysis above emphasizes the role of more advanced IDTs in achieving omni-channel total integration:

Proposition 4: IDTs support omni-channel data flow integration, specifically more advanced IDTs (BDA) support omni-channel system toward total integration.

Consistent with the supply chain inter-organizational governance theory (Ashenbaum et al., 2009; Choi and Kim, 2008; Mahapatra et al., 2010), the recommended frameworks shown in Figure 2 and Figure 4 indicate that the strength of the inter-agent and inter-channel connections, as well as their structures, can highly affect the omni-channel integration. The omni-channel vertical and horizontal integrations, as devised earlier, can be achievable through contractual governance (Cao and Lumineau, 2015). Formal mechanisms of contractual governance (e.g. binding agreements and official instructions) can direct, enable and even enforce (if needed) data sharing and integration among agents (e.g. a major retailer demands and imposes its delivery service providers to use satellite-navigation systems). Over and above vertical and horizontal integrations, total integration involves widely distributed and heterogeneous data exchanges, agents, and resources, where the contractual governance are typically expensive and inefficient (Wacker et al., 2016). Therefore, at the total integration level, patterns of inter-organizational connections need to emerge (Mahapatra et al., 2019) to assure data visibility and 
integration throughout the omni-channel system. This, in turn, makes both contractual and relational governance essential for omni-channel retailing, where formal agreements as well as informal cooperation among agents will lead to more complementary relationships (Formentini and Romano, 2016). Further investigation on the total integration and the role of contractual governance in it points out that at this level of integration, contractual governance is not about enforcing some requirements (e.g. how to use big data) but more about more clarification and definability, albeit formally, of integration decision and actions. This is in line with Zhang et al. (2020) definition of contractual governance based on definability and enforceability, where they define contractual definability as clarifying of the roles, responsibilities and codes of conduct for the associate parties. In view of those, more specific role of governance in omni-channel total integration can be stated as:

Proposition 5: Relational governance and contractual governance (in the form of contractual definability) support omni-channel total integration.

Figure 5 summarizes the final outcomes of this paper in a theoretical framework indicating the main focus areas of the research (i.e. omni-channel integrations, IDTs, omni-channel adaptability, and governance), the propositions, and their links with earlier findings (i.e. notions).

Figure 5 here

\section{Conclusions}

Drawing upon an in-depth explorative research and substantial qualitative data this study has developed a thorough empirical insight on omni-channel data flows and their supporting IDTs. Accordingly, data flow frameworks are developed to illustrate the omni-channel data flow integration, from both the consumer and retailer/business perspectives (Figures 1 and 2). The recommended frameworks show how integrated data flows can be materialized by horizontal, vertical and total integrations (addressing research question $i$ ). They also point out how interorganizational relationships should be managed to support data flow integrations toward enhancing the omni-channel adaptability (addressing research question iii). Relatedly, the required IDTs to support data flow frameworks are identified, and their specific implications for omni-channel integration are discussed (addressing research question $i i$ ).

The research outcomes above are formalized in five propositions (Figure 5). Overall, this research enhances the existing general ideas around omni-channel retailing to a more specific, robust and pragmatic level, where details of data transactions and integration, their supporting IDTs, their contribution to the omni-channel system, and their enablers, in terms of inter-organizational governance mechanisms, are specified.

\subsection{Theoretical contribution}

Given the lack of established theories in the omni-channel literature, this research goes beyond a basic description of "what omni-channel is" and "why it is important for the retail sector", and debates what specific data should be shared at what levels and between which agents of the omni-channel system to 
assure a well-integrated omni-channel system retailing. In view of that and building upon the evident necessity of integration for omni-channel systems (Galliano and Moreno, 2014), this paper has shown how integrated data flows can be materialized at horizontal, vertical and total integration levels.

This paper posits that framing the data flows, according to sources and users of data, help the omnichannel system identify how to integrate them thoroughly. The recommended detailed frameworks for horizontal, vertical and total integration directly respond to the need for data exchange among channels, online and offline channel integration, interconnection of products and information records, and synchronization of the supply and demand data, frequently raised by the literature (Gallino and Moreno, 2014; Herhausen et al., 2015; Onal et al., 2018; Verhagen and van Dolen, 2009). The recommended data flows and integrations of this research also minimize the data inconsistencies across different information siloes, as labeled by Briedis et al. (2019), and, for instance, improve the inventory data accuracy - a major concern in the omni-channel literature (Barratt et al., 2018). Moreover, the current research shows how the Mirzabeiki and Saghiri (2020) implicit propositions on the product data track and trace and automation can be implemented more explicitly and thoroughly, with an omni-channelwide, IDT-supported data flow horizontal, vertical and total integrations.

Beside the contributions above, this research emphasizes the specific role of IDTs in achieving data flow integration. In view of that, it goes beyond the conventional barcode, RFID and EDI tools and recommends the application of advanced IDTs including WSN, CPS, IoT, AI and BDA (Frank et al., 2019). Thanks to advanced sensors as well as data transmission technologies and the Internet, real-time data can be automatically captured and shared by connected things. However, it should be noted that automatic data production in a complex system such as the omni-channel, if not managed adequately, may just add to its complications. Although studies such as Xu et al. (2018) underline the necessity for proper analysis of the big data that is generated through advanced technologies, this paper points out that the omni-channel system should first look at the data capturing and sharing more systematically and holistically, and generate, share and analyze the relevant data based on a well-established framework of data transactions, and well-defined horizontal, vertical, and total integrations among them.

Determining specific IDTs for omni-channel horizontal, vertical and total integrations, also contributes to the literature by extending the recent research and propositions on the relationship between store/online data capturing technologies and data analytics (Jocevski, 2020); the need for more advanced information systems to support omni-channel data synchronization (Kembro and Norrman, 2019a); the necessity of IDTs infrastructure to achieve data consistency across the omni-channel system (Kazancoglu and Aydin, 2018; Larke et al., 2018); and the role of order trace and track technologies in the consumer choice of channel (Xu and Jackson, 2019).

In addition to the technical insights above, the contribution of this research is viewed from the CAS as well as inter-organizational governance theories' perspectives. Juxtaposition of the two theories helps this research to explain data flow integrations in omni-channel systems. In the recommended omnichannel data flow frameworks of this paper, the agents which share and gather data (i.e. the header rows of Figures 2a\&b) represent the agents of the omni-channel system, and the proposed intra- and interconnections among them form a common schema for the omni-channel complex system. In effect, the interaction and connectivity required to manage a complex system such as the omni-channel is achieved through the threefold integrations (horizontal, vertical, and total), mapped against the data flow frameworks of this paper. 
The self-organization and autonomy element of CAS is largely supported by the recommended moves toward total integration. Well-developed data flows, when coupled with advanced IDTs, can enable self-organized agents to make timely, autonomous decisions about physical flows (e.g. order fulfillment, shipment, lot-sizes, and stock-keeping point) and data flows (e.g. orders, ASN, invoices, and recalls). The self-organization feature of a well-integrated omni-channel system can be ideally defined at all levels, such as warehouse robots (to make storage and filling decisions), CPS in the production line (to make production decisions), order-fulfillment systems (to make ordering and delivery decisions), and Sat-Nav-supported delivery vehicles (to make route planning decisions).

Further synthesis of and discussion on the research outcomes also show that contractual governance and relational governance do not necessarily substitute each other (Cao and Lumineau, 2015), and while the former supports omni-channel horizontal and vertical integrations, it needs the latter for total integration. This is in line with analytical research on omni-channel retailing (Giannikas and McFarlane, 2021) which reveals that the implementation of IDT is the matter of acceptance by omni-channel agents (i.e. relational) as well as formal feasibility (i.e. contractual).

The inter-organizational governance to enforce or facilitate data flow integration and IDT implementation by omni-channel agents is, nevertheless, open to further discussion and argument, as it largely relies on a central or leading agent (Mahapatra et al., 2019), which may not exist in omnichannel retailing. Moreover, while it has been emphasized that IDT implementation has major impacts on inter-organizational governance (Lumineau et al., 2020), this paper underlines another direction of that relationship, where both contractual and relational governance models are found supportive for omni-channel integration and IDT implementation. In combination, CAS and inter-organizational governance theories enhance and extend the understanding of omni-channel data flows and integrations, and their links with omni-channel adaptability and governance mechanisms.

\subsection{Practical contribution}

This paper offers four practical contributions. First, understanding the omni-channel data flows, and where they originate from/go to, will help omni-channel managers make informed decisions and take more timely actions - in sourcing, purchase, storage, shipment, sales, logistics, and return operations. The magnitude and scope of data flows and the integrations among them in the omni-channel system, underlines its essential difference with store-only, online pure-play, and multi-channel retailing. This provides the single/multi-channel retail managers a more explicit view of their route to the omnichannel retailing, should they decide to move toward it.

Second, given the cases of fragmented and disjointed processes, reported in many omni-channels as pointed out earlier, the recommended data flow integrations of this paper provide practical insights for omni-channel managers to materialize seamless flows of products across both business and consumer sides. Hence, omni-channel managers should be aware that data flow integration should occur (a) horizontally among relevant agents/processes who make, keep, sell, deliver and return the product across different channels; and (b) vertically among data capturing, storing, sharing, and analyzing instruments, equipment, and technologies. These significantly affect the decisions on omni-channel structures and processes. IDTs have been found crucial to make these happen. This indicates the third practical contribution of this research, by emphasizing to omni-channel managers that IDTs do not only make data transactions faster or more accurate in their day-to-day business, but also connect and 
synchronize the horizontal and vertical integrations to form a totally integrated omni-channel. More advanced IDTs (e.g. CPS, IoT, AI, and BDA) then go beyond data flow management and integration, and facilitate autonomous decisions and actions. To achieve this level of autonomy at the total integration level, omni-channel managers need to prioritize training and investments in advanced IDTs.

Fourth, this research highlights for managers that data flow integrations and their supporting IDTs have direct effect on their business competitiveness by making the omni-channel more adaptable (to its surrounding uncertainties and changes). In line with it, implementation of data flow integrations and their supporting IDTs are found dependent on interorganizational governance mechanisms. Hence managers are advised to consider formal arrangement to enforce execution of IDTs across the relevant omni-channel agent. Moving further toward the total integration, omni-channel integration also need to work on relational governance mechanisms to promote and facilitate more advanced IDTs applications.

\subsection{Future research}

The recommended frameworks and suggestions of this research can initiate a number of debates on their enablers and barriers, and implementation challenges.

Future research can expand the recommended framework of Figure $2 b$ to other businesses (in addition to the retailer), and study the expansion of the omni-channel total integration (as suggested by Figure 4) according to them. The future research also needs to address the uncertainty around advanced IDT implementations in omni-channels, as a complex system. Application of advanced IDTs and achieving total omni-channel integration also needs data and data management standardization. This needs further research on standardization of data structures and type, as well as data capture and communication procedures, as the major drivers of omni-channel systems.

Inter-organization relationship governance in omni-channel systems have been also found largely unexplored, and further research is needed to progress the pioneering understanding of this paper on omni-channel governance mechanisms and their effects.

\section{Acknowledgement}

The authors would like to thank the International Journal of Operations and Production Management's editor-in-chief, associate editor, special issue editors, and anonymous reviewers for their critical reviews and constructive comments on the earlier editions of this paper.

\section{References}

Acquila-Natale, E. and Iglesias-Pradas, S. (2020), "How to measure quality in multi-channel retailing and not die trying", Journal of Business Research, 109, 38-48.

Akin Ates, M., Van den Ende, J. and Ianniello, G. (2015), "Inter-organizational coordination patterns in buyer-supplier-design agency triads in NPD projects", International Journal of Operations \& Production Management, 35(11), 1512-1545. 
Ancarani, A., Di Mauro, C., Legenvre, H. and Cardella, M.S. (2020), "Internet of things adoption: a typology of projects", International Journal of Operations \& Production Management, 40(6), 849872.

Ashenbaum, B., Maltz, A., Ellram, L. and Barratt, M.A. (2009), "Organizational alignment and supply chain governance structure”, The International Journal of Logistics Management, 20(2), 169-186.

Avery, J., Steenburgh, T.J., Deighton, J. and Caravella, M. (2012), “Adding bricks-to-clicks: predicting the patterns of cross-channel elasticities over time", Journal of Marketing, 76(3), 96-111.

Barratt, M., Kull, T.J. and Sodero, A.C. (2018), "Inventory record inaccuracy dynamics and the role of employees within multi-channel distribution center inventory systems", Journal of Operations Management, 63, 6-24.

Bell, D., Gallino, S. and Moreno, A. (2015), "Showrooms and information provision in omni-channel retail”, Production and Operations Management, 24(3), 360-362.

Berger, J., Sorensen, A.T. and Rasmussen, S.J. (2010), "Positive effects of negative publicity: when negative reviews increase sales", Marketing Science, 29(5) 815-827.

Bernon, M., Cullen, J. and Gorst, J. (2016), “Online retail returns management”, International Journal of Physical Distribution \& Logistics Management, 46(6/7), 584-605.

Bijmolt, T.H., Broekhuis, M., De Leeuw, S., Hirche, C., Rooderkerk, R.P., Sousa, R. and Zhu, S.X. (2021), "Challenges at the marketing-operations interface in omni-channel retail environments", Journal of Business Research, 122, 864-874.

Blackwell, R.D., Miniard, P.W. and Engel, J.F. (2001), Consumer behavior, South-Western Thomas Learning, Mason, $\mathrm{OH}$.

Bogataj, D., Marija B. and Domen, H. (2017), "Mitigating risks of perishable products in the cyberphysical systems based on the extended MRP model", International Journal of Production Economics, 193, 51-62.

Bradlow, E.T., Gangwar, M., Kopalle, P. and Voleti, S. (2017), "The role of big data and predictive analytics in retailing”, Journal of Retailing, 93(1), 79-95.

Briedis, H., Harris, T., Pacchia, M. and Ungerman, K. (2019), Ready to 'where': getting sharp on apparel omnichannel excellence, McKinsey \& Company, August 2019.

Brinch, M. (2018), "Understanding the value of big data in supply chain management and its business processes”, International Journal of Operations \& Production Management, 38(7), 1589-1614.

Bryman, A. and Bell, E. (2007), Business research methods, 2nd Eds., Oxford University Press.

Cai, Y.J. and Lo, C.K. (2020), "Omni-channel management in the sharing economy era: a systematic review and future research agenda", International Journal of Production Economics, 229, 107729.

Cao, Z. and Lumineau, F. (2015), "Revisiting the interplay between contractual and relational governance: a qualitative and meta-analytic investigation", Journal of Operations Management, 33, $15-42$.

Cao, L. and Li, L. (2015), “The impact of cross-channel integration on retailers' sales growth”, Journal of Retailing, 91(2), 198-216.

Cao, L. and Li, L. (2018). “Determinants of retailers' cross-channel integration: an innovation diffusion perspective on omni-channel retailing", Journal of Interactive Marketing, 44, 1-16. 
Caro, F., Kök, A.G. and Martínez-de-Albéniz, V. (2020), "The future of retail operations", Manufacturing \& Service Operations Management, 22(1), 47-58.

Chang, Y.W., Hsu, P.Y. and Yang, Q.M. (2018), "Integration of online and offline channels: a view of O2O commerce", Internet Research, 28(4), 926-945.

Chen, J.C., Cheng, C.H. and Huang P.B. (2013), "Supply chain management with lean production and RFID application", Expert Systems with Applications, 40(9), 3389-3397.

Cheng, Y., Farooq, S. and Johansen, J. (2015), "International manufacturing network: past, present, and future", International Journal of Operations \& Production Management, 35(3), 392-429.

Chi, M., Huang, R., and George, J.F. (2020), "Collaboration in demand-driven supply chain: based on a perspective of governance and IT-business strategic alignment", International Journal of Information Management, 52, 102062.

Choi, T. Y., Dooley, K. J. and Rungtusanatham, M. (2001), "Supply networks and complex adaptive systems: control versus emergence", Journal of Operations Management, 19(3), 351-366.

Condea, C., Thiesse, F. and Fleisch E. (2012), "RFID-enabled shelf replenishment with backroom monitoring in retail stores", Decision Support Systems, 52(4), 839-849.

Craig, N., DeHoratius, N., Jiang, Y. and Klabjan, D. (2015), "Execution quality: an analysis of fulfillment errors at a retail distribution center", Journal of Operations Management, 38, 25-40.

Croxton, K.L. (2003), "The order fulfillment process", International Journal of Logistics Management, 14(1), 19-32.

Dai, H. and Tseng M.M. (2012), "The impacts of RFID implementation on reducing inventory inaccuracy in a multi-stage supply chain", International Journal of Production Economics, 139(2), 634-641.

Eisenhardt, K.M. (1989), "Building theories from case study research", Academy of Management Review, 14(4), pp.532-550.

Eisenhardt, K.M. and Graebner, M.E. (2007), "Theory building from cases: opportunities and challenges", Academy of Management Journal, 50(1), 25-32.

Ellram, L.M. (1996), "The use of the case study method in logistics research", Journal of Business Logistics, 17(2), 93-138.

Ettlie, J.E., Perotti, V.J., Joseph, D.A. and Cotteleer, M.J. (2005), "Strategic predictors of successful enterprise system deployment", International Journal of Operations \& Production Management, 25(10), 953-972.

Fan, T., Tao, F., Deng, S. and Li, S. (2015), "Impact of RFID technology on supply chain decisions with inventory inaccuracies", International Journal of Production Economics, 159, 117-125.

Fang, J., Liu, H., Li, Y. and Cai, Z. (2021), "Retaining customers with in-store mobile usage experience in omni-channel retailing: the moderating effects of product information overload and alternative attractiveness", Electronic Commerce Research and Applications, 46, 101028.

Flick, U. (2009), An Introduction to Qualitative Research. Sage: London.

Formentini, M. and Romano, P. (2016), "Towards supply chain collaboration in B2B pricing", International Journal of Operations \& Production Management, 36(7), 734-756. 
Frank, A.G., Dalenogare, L.S. and Ayala, N.F. (2019), "Industry 4.0 technologies: implementation patterns in manufacturing companies", International Journal of Production Economics, 210, 15-26.

Gallino, S. and Moreno, A. (2014), "Integration of online and offline channels in retail: the impact of sharing reliable inventory availability information", Management Science, 60(6), 1434-1451.

Giannikas, V. and McFarlane, D. (2021), "Examining the value of flexible logistics offerings", European Journal of Operational Research, 290(3), 968-981.

Gibbert, M., Ruigrok, W. and Wicki, B. (2008). "What passes as a rigorous case study?", Strategic Management Journal, 29(13), 1465-1474.

GS1 (2015). Global trade item number. GS1 AISBL.

Haki, K., Beese, J., Aier, S. and Winter, R. (2020), "The evolution of information systems architecture: an agent-based simulation model". MIS Quarterly, 4(1), 155-184.

Hald, K.S. and Mouritsen, J. (2013), "Enterprise resource planning, operations and management", International Journal of Operations \& Production Management, 33(8), 1075-1104.

Heller, J., Chylinski, M., de Ruyter, K., Mahr, D. and Keeling, D.I. (2019), “Touching the untouchable: exploring multi-sensory augmented reality in the context of online retailing", Journal of Retailing, 95(4), 219-234.

Herhausen, D., Binder, J., Schoegel, M. and Herrmann, A. (2015), "Integrating bricks with clicks: retailer-level and channel-level outcomes of online-offline channel integration", Journal of Retailing, 91(2), 309-325.

Hofmann, E. and Rüsch, M. (2017), "Industry 4.0 and the current status as well as future prospects on logistics", Computers in Industry, 89, 23-34.

Hübner, A., Mena, Michael Bourlakis, C., Wollenburg, J. and Holzapfel, A. (2016), "Retail logistics in the transition from multi-channel to omni-channel", International Journal of Physical Distribution \& Logistics Management, 46(6/7), 562-583.

Ivanov, D., Tang, C.S., Dolgui, A., Battini, D. and Das, A. (2020), "Researchers' perspectives on Industry 4.0: multi-disciplinary analysis and opportunities for operations management", International Journal of Production Research, 59(7), 2055-2078.

International Organization for Standardization (1998), ISO/IEC6523-1:1998, available at www.iso.org/standard/25773.html, accessed on 12/04/2020.

Jocevski, M. (2020), "Blurring the lines between physical and digital spaces: business model innovation in retailing", California Management Review, In Press.

Kang, Y., Lee, S. and Chung B.D. (2019), "Learning-based logistics planning and scheduling for crowdsourced parcel delivery”, Computers \& Industrial Engineering, 132, 271-279.

Kaufmann, L. and Denk, N. (2011), "How to demonstrate rigor when presenting grounded theory research in the supply chain management literature", Journal of Supply Chain Management, 47(4), 6472.

Kazancoglu, I. and Aydin, H. (2018), "An investigation of consumers' purchase intentions towards omni-channel shopping", International Journal of Retail \& Distribution Management, 46(10), 959976. 
Kembro, J.H. and Norrman, A. (2019a). "Exploring trends, implications and challenges for logistics information systems in omni-channels", International Journal of Retail \& Distribution Management, 47(4), 384-411.

Kembro, J.H. and Norrman, A. (2019b), "Warehouse configuration in omni-channel retailing: a multiple case study", International Journal of Physical Distribution \& Logistics Management, 50(5), 509-533.

Khanchanapong, T., Prajogo, D., Sohal, A.S., Cooper, B.K., Yeung, A.C.L. and Cheng, T.C.E. (2014), "The unique and complementary effects of manufacturing technologies and lean practices on manufacturing operational performance", International Journal of Production Economics, 153, 191203.

King, R.C., Sen, R. and Xia, M. (2004), "Impact of web-based e-commerce on channel strategy in retailing", International Journal of Electronic Commerce, 8(3), 103-130.

Kitzinger, J. (1995), "Qualitative research: introducing focus groups", British Medical Journal, 311, 299-302.

Lumineau, F., Wang, W. and Schilke, O. (2020), "Blockchain governance - a new way of organizing collaborations?”, Organization Science, 54, 102191.

Larke, R., Kilgour, M. and O'Connor, H. (2018), "Build touchpoints and they will come: transitioning to omnichannel retailing", International Journal of Physical Distribution \& Logistics Management, 48(4), 465-483.

Leitao, P., Colombo, A.W. and Karnouskos, S. (2016), "Industrial automation based on cyber-physical systems technologies: prototype implementations and challenges", Computers in Industry, 81, 11-25.

Lemon, K.N. and Verhoef, P.C. (2016), "Understanding customer experience throughout the customer journey”, Journal of Marketing, 80(6), 69-96.

Leung, K. H., Choy, K. L., Siu, P. K., Ho, G. T., Lam, H. Y., and Lee, C. K. (2018), “A B2C e-commerce intelligent system for re-engineering the e-order fulfilment process", Expert Systems with Applications, 91, 386-401.

Li, G., Zhang, T. and Tayi, G.K. (2020), "Inroad into omni-channel retailing: physical showroom deployment of an online retailer", European Journal of Operational Research, 283(2), 676-691.

Li, Y., Li, G., Tayi, G.K. and Cheng, T.C.E., (2019), "Omni-channel re-tailing: do offline retailers benefit from online reviews?", International Journal of Production Economics, 218, 43-61.

Li, Y., Liu, H., Lim, E.T., Goh, J.M., Yang, F. and Lee, M.K. (2018), "Customer's reaction to crosschannel integration in omnichannel retailing: the mediating roles of retailer uncertainty, identity attractiveness, and switching costs", Decision Support Systems, 109, 50-60.

Liao, Y., Deschamps, F., Loures, E. and Ramos, L. (2017), "Past, present and future of industry 4.0 -a systematic literature review", International Journal of Production Research, 55(12), 3609-3629.

Lim, S.F.W. and Srai, J.S. (2018), "Examining the anatomy of last-mile distribution in e-commerce omnichannel retailing", International Journal of Operations \& Production Management, 38(9), 1735 1764.

Liu, S., Leat, M., Moizer, J., Megicks, P. and Kasturiratne, D. (2013), “A decision-focused knowledge management framework to support collaborative decision making for lean supply chain management", International Journal of Production Research, 51(7), 2123-2137. 
MacCarthy, B.L., Blome, C., Olhager, J., Srai, J.S. and Zhao, X. (2016), "Supply chain evolutiontheory, concepts and science", International Journal of Operations \& Production Management, 36(12), 1696-1718.

Mahapatra, S. K., Narasimhan, R. and Barbieri, P. (2019), “A contingent assessment of the structural and governance characteristics of interconnected dyads in multitier supply chains", International Journal of Operations \& Production Management. 39(5), 714-738.

Mahapatra, S. K., Narasimhan, R. and Barbieri, P. (2010), "Strategic interdependence, governance effectiveness and supplier performance: a dyadic case study investigation and theory development", Journal of Operations Management, 28(6), 537-552.

Marchet, G., Melacini, M., Perotti, S., Rasini, M. and Tappia, E. (2018), "Business logistics models in omni-channel: a classification framework and empirical analysis", International Journal of Physical Distribution \& Logistics Management. 48(4), 439-464.

Margetis, G., Ntoa, S., Stephanidis, C. (2019), "Smart omni-channel consumer engagement in malls", Communications in Computer and Information Science, 1034, 89-96.

Marshall, C. and Rossman, G.B. (2006), Designing qualitative research, Sage: London.

McLean, G., Osei-Frimpong, K., Al-Nabhani, K. and Marriott, H. (2020), "Examining consumer attitudes towards retailers' m-commerce mobile applications-An initial adoption vs. continuous use perspective", Journal of Business Research, 106, 139-157.

Melacini, M., Perotti, S., Rasini, M. and Tappia, E. (2018), "E-fulfilment and distribution in omnichannel retailing: a systematic literature review", International Journal of Physical Distribution \& Logistics Management, 48(4), 391-414.

Miles, M.B., Huberman, A.M. and Saldana, J. (2013), Qualitative data analysis, Sage.

Miller, J.H. and Page, S.E. (2009), Complex adaptive systems: an introduction to computational models of social life. Princeton University Press.

Mirzabeiki, V. and Saghiri, S.S. (2020), "From ambition to action: how to achieve integration in omnichannel?”, Journal of Business Research, 110, 1-11.

Mooney, M. (2020), "Parcel giants team up in national effort to collect Covid-19 tests". Logistics Manager, 2 July 2020, available at https://www.logisticsmanager.com/parcel-giants-team-up-innational-effort-to-collect-covid-19-tests, accessed on 30/09/2020.

Müller-Lankenau, C., Wehmeyer, K. and Klein, S. (2006), "Strategic channel alignment: an analysis of the configuration of physical and virtual marketing channels", Information Systems and e-Business Management, 4(2), 187-216.

Murray, C.D. and Sixsmith, J. (1998), "E-mail: a qualitative research medium for interviewing?" International Journal of Social Research Methodology, 1(2), 103-121.

Nilsson, F. and Darley, V. (2006), "On complex adaptive systems and agent-based modelling for improving decision-making in manufacturing and logistics settings: experiences from a packaging company", International Journal of Operations \& Production Management, 26(12), 1351-1373.

Novick, G. (2008), "Is there a bias against telephone interviews in qualitative research?" Research in Nursing \& Health, 31(4), 391-398. 
Oh, L., Teo, H. and Sambamurthy, V. (2012), "The effects of retail channel integration through the use of information technologies on firm performance", Journal of Operations Management, 30(5), 368381.

Onal, S., Zhang, J. and Das, S. (2018), "Product flows and decision models in Internet fulfillment warehouses", Production Planning \& Control, 29(10), 791-801.

Patel, C. (2014), "Successful service retail channel expansions: the roles of technical and brand integration", Industrial Marketing Management, 43(1), 102-112.

Pereira, M.M. and Frazzon, E.M. (2021), "A data-driven approach to adaptive synchronization of demand and supply in omni-channel retail supply chains", International Journal of Information Management, 57, 102165.

Power, E.M. (2004), "Toward understanding in postmodern interview analysis: interpreting the contradictory remarks of a research participant", Qualitative Health Research, 14(6), 858-865.

Pratt, M.G. (2009), "From the editors: for the lack of a boilerplate: tips on writing up (and reviewing) qualitative research", The Academy of Management Journal, 52(5), 856-862.

Saghiri, S., Wilding, R., Mena, C. and Bourlakis, M. (2017), "Toward a three-dimensional framework for omni-channel", Journal of Business Research, 77, 53-67.

Schwerdfeger, S., Boysen, N. (2020). "Optimizing the changing locations of mobile parcel lockers in last-mile distribution”, European Journal of Operational Research, 285(3), 1077-1094

Seyedghorban, Z., Tahernejad, H., Meriton, R. and Graham, G. (2020), "Supply chain digitalization: past, present and future", Production Planning \& Control, 31(2-3), 96-114.

Shen, X.L., Li, Y.J., Sun, Y. and Wang, N. (2018), "Channel integration quality, perceived fluency and omnichannel service usage: the moderating roles of internal and external usage experience", Decision Support Systems, 109, 61-73.

Singh, A. and Tucker, C.S. (2017), "A machine learning approach to product review disambiguation based on function, form and behavior classification", Decision Support Systems, 97, 81-91.

Sousa, R. and Amorim, M. (2018), "Architectures for multichannel front-office service delivery models", International Journal of Operations \& Production Management, 38(3), 828-851.

Sousa, R. and Voss, C.A. (2006), "Service quality in multichannel services employing virtual channels", Journal of Service Research, 8(4), 356-371.

Stake, R.E. (2013), Multiple case study analysis. Guilford Press.

Strozzi, F., Colicchia, C., Creazza, A. and Noè, C. (2017), "Literature review on the 'smart factory' Concept Using Bibliometric Tools", International Journal of Production Research,55(22), 65726591.

Sturges, J.E. and Hanrahan, K.J. (2004), "Comparing telephone and face-to-face qualitative interviewing: a research note", Qualitative Research, 4(1), 107-118.

Sun, H., Zhang, J. and Akashi, T. (2020), "TemplateFree: product detection on retail store shelves", IEEJ Transactions on Electrical and Electronic Engineering, 15(2), 242-251.

Sun, M. and Tyagi, R.K. (2020), "Product fit uncertainty and information provision in a distribution channel", Production and Operations Management. In Press. 
Um, K.H., and Oh, J.Y. (2020), "The interplay of governance mechanisms in supply chain collaboration and performance in buyer-supplier dyads: substitutes or complements", International Journal of Operations \& Production Management. 40(4), 415-438.

Verhagen, T. and van Dolen, W. (2009), "Online purchase intentions: a multi-channel store image perspective", Information \& Management, 46(2), 77-82.

Verhoef, P.C., Kannan, P.K. and Inman, J.J. (2015), "From multi-channel retailing to omni-channel retailing: introduction to the special issue on multi-channel retailing", Journal of Retailing, 91(2), 174181.

Villalobos, K., Ramírez-Durán, V.J., Diez, B., Blanco, J.M., Goñi, A. and Illarramendi, A. (2020), “A three level hierarchical architecture for an efficient storage of industry 4.0 data", Computers in Industry, 121, 103257.

Vize, R., Coughlan, J., Kennedy, A. and Ellis-Chadwick, F. (2013), “Technology readiness in a B2B online retail context: an examination of antecedents and outcomes", Industrial Marketing Management, 42(6), 909-918.

Wacker, J.G., Yang, C. and Sheu, C. (2016), "A transaction cost economics model for estimating performance effectiveness of relational and contractual governance", International Journal of Operations \& Production Management, 36(11), 1551-1575.

Wamba, S.F. and Akter, S. (2019), "Understanding supply chain analytics capabilities and agility for data-rich environments", International Journal of Operations \& Production Management, 39(6/7/8), 887-912.

Watson, C. (2006), “Unreliable narrators? 'Inconsistency' (and some inconstancy) in interviews”, Qualitative Research, 6(3), 367-384.

Wollenburg, J., Holzapfel, A., Hübner, A. and Kuhn, H. (2018a), "Configuring retail fulfillment processes for omni-channel customer steering”. International Journal of Electronic Commerce, 22(4), $540-575$.

Wollenburg, J., Hübner, A., Kuhn, H. and Trautrims, A. (2018b), "From bricks-and-mortar to bricksand-clicks: logistics networks in omni-channel grocery retailing", International Journal of Physical Distribution \& Logistics Management, 48(4), 415-438.

$\mathrm{Xu}, \mathrm{X}$. and Jackson, J. E. (2019). "Examining customer channel selection intention in the omni-channel retail environment". International Journal of Production Economics, 208, 434-445.

Xu, L.D., Xu, E.L. and Li, L. (2018), "Industry 4.0: state of the art and future trends", International Journal of Production Research, 56(8), 2941-2962.

Yin, R.K. (2014), Case study research: Design and methods, California: Sage Publications.

Zhang, C. and Zheng, X. (2020), "Customization strategies between online and offline retailers", Omega, In Press.

Zhang, Q., Jin, J. L. and Yang, D. (2020), "How to enhance supplier performance in China: interplay of contracts, relational governance and legal development", International Journal of Operations \& Production Management, 40(6), 777-808.

Zhang, J., Onal, S., Das, R., Helminsky, A. and Das, S. (2019), "Fulfilment time performance of online retailers - an empirical analysis", International Journal of Retail \& Distribution Management, 47(5), 493-510. 
Zhang, M., Ren, C., Wang, G.A. and He, Z. (2018), "The impact of channel integration on consumer responses in omni-channel retailing: the mediating effect of consumer empowerment", Electronic Commerce Research and Applications, 28, 181-193.

Zhang, T., Li, G., Cheng, T. E. and Shum, S. (2020a), "Consumer inter-product showrooming and information service provision in an omni-channel supply chain". Decision Sciences, 51(5), 12321264.

Zhang, T.B., Ling, G.J., Dai, F.J., Yang, S.C., Zhang, A.W. and Zhou, H.H. (2020), Omnichannel transformation begins by grasping the key to consumer mentalities, Deloitte China, 2020.

Zhu, S., Hu, X., Huang, K., \& Yuan, Y. (2021), “Optimization of product category allocation in multiple warehouses to minimize splitting of online supermarket customer orders", European Journal of Operational Research, 290(2), 556-571. 


\section{Appendix 1: Summary of the literature on omni-channel integration}

\begin{tabular}{|c|c|c|c|}
\hline & Necessity for and Requirements of Integration & Opportunities and Challenges of Integration & Impacts of Integration \\
\hline $\begin{array}{l}\text { Barratt et al. } \\
\text { (2018) }\end{array}$ & $\begin{array}{l}\text { Integration is needed among different stock- } \\
\text { keeping points. }\end{array}$ & & \\
\hline $\begin{array}{l}\text { Bell et al. } \\
(2015)\end{array}$ & $\begin{array}{l}\text { Full visibility across all channels and a uniform } \\
\text { shopping experience to consumers, regardless of } \\
\text { the sales channel are necessary for omni-channel. }\end{array}$ & & \\
\hline $\begin{array}{l}\text { Bernon et al. } \\
(2016)\end{array}$ & $\begin{array}{l}\text { Returns process should be integrated to the rest of } \\
\text { the omni-channel system. }\end{array}$ & & \\
\hline $\begin{array}{l}\text { Bijmolt et al. } \\
(2021)\end{array}$ & $\begin{array}{l}\text { Integration is needed in assortment, inventory, } \\
\text { distribution, delivery and returns processes. }\end{array}$ & & \\
\hline $\begin{array}{l}\text { Chang et al. } \\
(2018)\end{array}$ & & $\begin{array}{l}\text { Channel integration is a major problem in online- } \\
\text { offline service in the travel industry. }\end{array}$ & \\
\hline $\begin{array}{l}\text { Cai and Lo } \\
(2020)\end{array}$ & Integration is a core feature of omni-channel. & & \\
\hline $\begin{array}{l}\text { Cao and } \mathrm{Li} \\
(2015)\end{array}$ & & & $\begin{array}{l}\text { Cross-channel integration boosts the retailers' sales } \\
\text { growth. }\end{array}$ \\
\hline $\begin{array}{l}\text { Cao and } \mathrm{Li} \\
(2018)\end{array}$ & \multicolumn{2}{|c|}{ IT applications positively affect omni-channel/cross-channel integration. } & \\
\hline $\begin{array}{l}\text { Fang et al. } \\
(2021)\end{array}$ & \multicolumn{2}{|c|}{$\begin{array}{l}\text { While data/channel integrity is a requirement for omni-channel, new challenges such as losing in-store } \\
\text { mobile customers, with real-time access to product data, should be considered too. }\end{array}$} & \\
\hline $\begin{array}{l}\text { Herhausen } \\
\text { et al. }(2015)\end{array}$ & & \multicolumn{2}{|c|}{$\begin{array}{l}\text { The major opportunity for omni-channel is integrating online and offline channels, but there are impacts } \\
\text { on both channels which should not be ignored. }\end{array}$} \\
\hline $\begin{array}{l}\text { Hübner et al. } \\
(2016)\end{array}$ & $\begin{array}{l}\text { Omni-channel needs warehouse system(s) for } \\
\text { [cross-]channel-integrated inventory management. }\end{array}$ & & \\
\hline $\begin{array}{l}\text { Li et al. } \\
(2018)\end{array}$ & $\begin{array}{l}\text { Omni-channel needs interconnected entities such } \\
\text { as physical store, online sales, distribution center, } \\
\text { and manufacturer. }\end{array}$ & & \\
\hline $\begin{array}{l}\text { Li et al. } \\
\text { (2019) }\end{array}$ & \multicolumn{2}{|c|}{$\begin{array}{l}\text { Online reviews add to the omni-channel visibility and should be integrated to the rest of the omni- } \\
\text { channel. }\end{array}$} & \\
\hline
\end{tabular}




\begin{tabular}{|c|c|c|c|}
\hline & Necessity for and Requirements of Integration & Opportunities and Challenges of Integration & Impacts of Integration \\
\hline $\begin{array}{l}\text { Marchet et } \\
\text { al. (2018) }\end{array}$ & \multirow{2}{*}{$\begin{array}{l}\text { Integration } \\
\text { is a foundation of } \\
\text { omni-channel system. }\end{array}$} & & \\
\hline $\begin{array}{l}\text { Melacini et } \\
\text { al. (2018) }\end{array}$ & & & \\
\hline $\begin{array}{l}\text { Mirzabeiki } \\
\text { and Saghiri } \\
(2020)\end{array}$ & $\begin{array}{l}\text { Omni-channels need well-defined integration } \\
\text { plans. }\end{array}$ & & \\
\hline $\begin{array}{l}\text { Onal et al. } \\
(2018)\end{array}$ & $\begin{array}{l}\text { Integration is needed within and among the } \\
\text { warehouse systems }\end{array}$ & & \\
\hline $\begin{array}{l}\text { Shen et al. } \\
\text { (2018) }\end{array}$ & & & $\begin{array}{l}\text { Channel integration (including service transparency, } \\
\text { channel choice variety and content, and process } \\
\text { consistency) significantly affects the users' } \\
\text { experience. }\end{array}$ \\
\hline $\begin{array}{l}\text { Sousa and } \\
\text { Amorim } \\
(2018)\end{array}$ & \multicolumn{2}{|c|}{$\begin{array}{l}\text { Full integration among physical and data flows is needed. It provides an opportunity for omni-channel } \\
\text { entities to see and share product, inventory, sales and/or logistics data throughout the omni-channel } \\
\text { system. }\end{array}$} & \\
\hline $\begin{array}{l}\text { Sousa and } \\
\text { Voss (2006) }\end{array}$ & \multirow{2}{*}{$\begin{array}{l}\text { Information management platforms } \\
\text { and systems (e.g. cross-firm ERP } \\
\text { systems) are needed for online- } \\
\text { offline integration. }\end{array}$} & & \\
\hline $\begin{array}{l}\text { Verhagen } \\
\text { and van } \\
\text { Dolen (2009) }\end{array}$ & & & \\
\hline $\begin{array}{l}\text { Wollenburg } \\
\text { et al. } \\
(2018 \mathrm{~b})\end{array}$ & $\begin{array}{l}\text { Integrated management of inventory, delivery, } \\
\text { and return are necessary for omni-channel. }\end{array}$ & & \\
\hline
\end{tabular}


Appendix 2: The list of interview questions.

Appendix 2a: Questions of the company interviews.

\begin{tabular}{|c|c|}
\hline No. & Questions \\
\hline \multicolumn{2}{|r|}{ Part 1} \\
\hline 1 & Please provide a brief overview of your business, including your turnover, number of employees, brand position in the market, and number of stores. \\
\hline 2 & $\begin{array}{l}\text { Please provide us some information about the channels through which you sell your products, including store vs online share of sales, and the portion of items sold } \\
\text { via click and collect and home delivery (if applicable), your returns rates and any other information about your channels. }\end{array}$ \\
\hline 3 & $\begin{array}{l}\text { What are the operations conducted in the channels above (these can include purchasing, information sharing with suppliers, purchase order management, } \\
\text { transportation, warehousing, track and trace)? Where are the current item handover points (if applicable)? }\end{array}$ \\
\hline 4 & $\begin{array}{l}\text { How the data related to the item handover mentioned above is exchanged (these can include information sharing with logistics companies and other business partners } \\
\text { and third-party companies.)? What type of information you need to receive and what information you need to send to other actors in your omni-channel? How } \\
\text { effectively are these data exchange managed? What are the issues associated with this data management? }\end{array}$ \\
\hline 5 & $\begin{array}{l}\text { How integrated your channels are in terms of data accuracy or data quality (e.g., data being correct, detailed enough, updated, and synchronized in different } \\
\text { databases)? }\end{array}$ \\
\hline 6 & $\begin{array}{l}\text { Please explain what types of information and digital technologies (including systems like auto-ID) you are using for managing data about the operations mentioned } \\
\text { above, within your organization or with other organizations in your networks? These could include systems used for creating, capturing, and exchanging data } \\
\text { between different business units or companies in your network. } \\
\text { What systems do you aim to use in the future (if applicable)? }\end{array}$ \\
\hline \multicolumn{2}{|r|}{ Part 2} \\
\hline 7 & $\begin{array}{l}\text { What are the potential benefits of these information and digital technologies? Have you fully achieved your objectives from them in terms of managing flows of } \\
\text { product and data in your omni-channel? How they help overcoming the issues related to data management in your omni-channel which you mentioned before? }\end{array}$ \\
\hline \multicolumn{2}{|r|}{ Part 3} \\
\hline 8 & $\begin{array}{l}\text { What are the issues or challenges related to applying the mentioned information and digital technologies - for example in terms of managing omni-channel data? } \\
\text { (e.g., technical difficulties or issues related to collaboration with other organizations). }\end{array}$ \\
\hline 9 & $\begin{array}{l}\text { What are any identified solutions to overcome these challenges? } \\
\text { Do you have a defined strategy to overcome these challenges? }\end{array}$ \\
\hline
\end{tabular}


Appendix 2b- Questions of the consumer interviews.

\begin{tabular}{|c|c|}
\hline No. & Question \\
\hline 1 & What is your age, occupation, and education level? \\
\hline 2 & How often do you purchase products via omni-channels, including online, home delivery and click and collect? What do you usually buy via omni-channels? \\
\hline 3 & $\begin{array}{l}\text { What types of data you need to receive during the process of your purchase, including searching for a product, buying and payment, delivery and return and after sales } \\
\text { services? }\end{array}$ \\
\hline 4 & $\begin{array}{l}\text { What is your evaluation of quality of data provided to you by companies in omni-channels (e.g. accuracy, synchronization, and timeliness of data)? Are there any } \\
\text { issues in relation to quality of data during the whole process of purchasing, using, or returning your product? Please elaborate. }\end{array}$ \\
\hline 5 & What types of data do you provide to the company or the omni-channel that you purchase from? \\
\hline 6 & $\begin{array}{l}\text { What are the information and digital technologies for purchasing in omni-channels which you have used before? Please name those and explain how they help } \\
\text { consumers. Please explain if there are any issues associated with using these technologies. }\end{array}$ \\
\hline 7 & $\begin{array}{l}\text { What are your suggestions for improvements to companies in terms of providing data with higher quality to consumers, through the whole process of searching, buying, } \\
\text { using, or returning products, to make your shopping experience easier and more pleasant? }\end{array}$ \\
\hline
\end{tabular}


Table I. Case study companies and their omni-channel details.

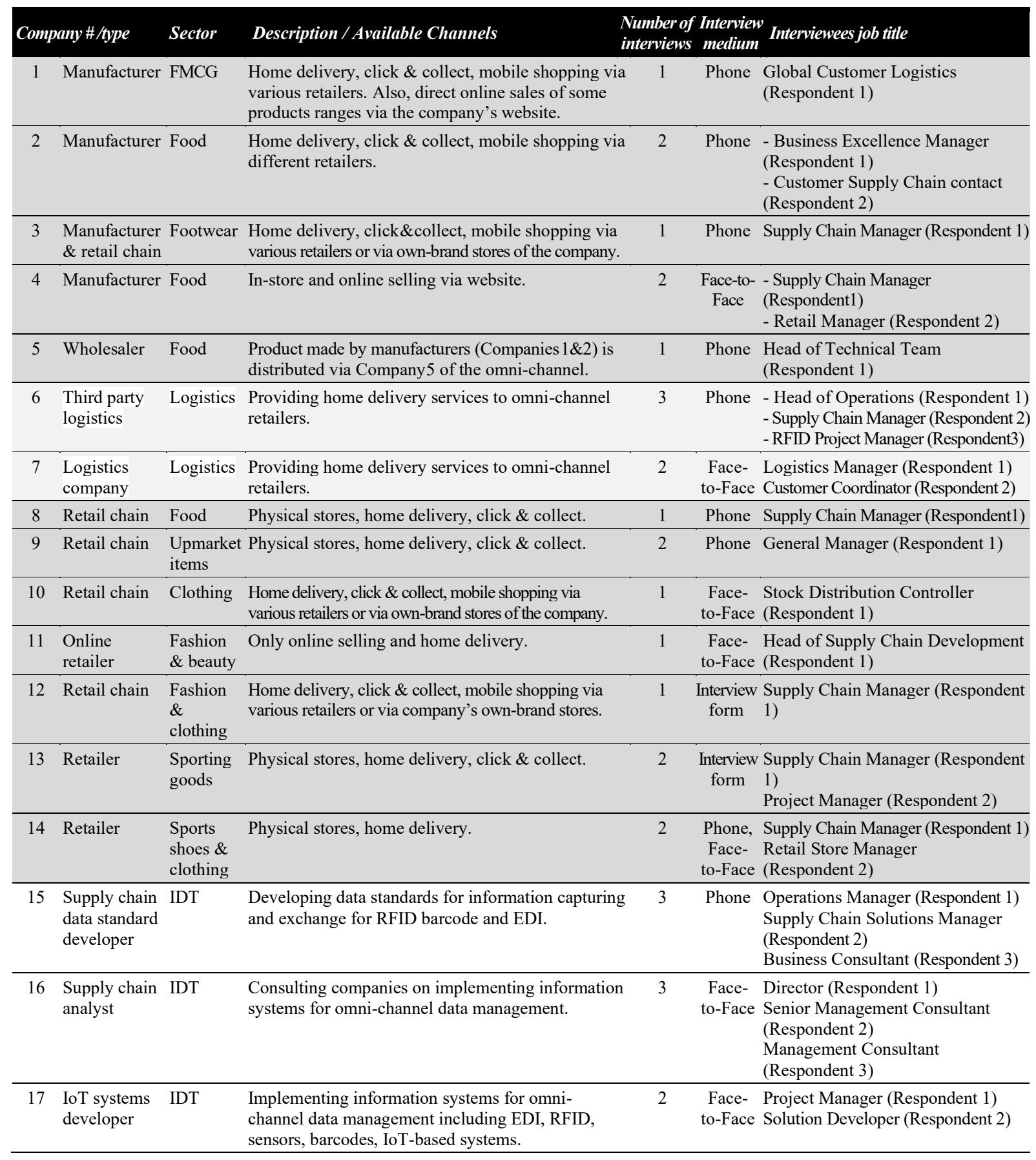


Table II. Sources of the research data, their details and their contributions to the findings.

\begin{tabular}{|c|c|c|}
\hline $\begin{array}{l}\text { Data collection } \\
\text { method }\end{array}$ & Details & $\begin{array}{l}\text { Aim and contribution to the findings } \\
\text { of the study }\end{array}$ \\
\hline Interviews & $\begin{array}{l}\text { In total } 68 \text { interviews with companies involved in omni-channels and customers } \\
\text { of retailers who sell their products via omni-channels: } \\
\text { Companies } \\
\text { Interviews with } 30 \text { representatives from participating companies, leading to more } \\
\text { than } 3100 \text { pages of transcripts and } 1350 \text { minutes of recorded conversation. } \\
\text { Consumers } \\
\text { Interviews with } 38 \text { consumers buying apparel, food, and fast-moving consumer } \\
\text { goods (FMCG) via omni-channels (in store, online, and click \& collect), leading to } \\
\text { more than } 2460 \text { pages of transcripts and about } 970 \text { minutes of recorded } \\
\text { conversation. } \\
\text { They cover all age ranges from } 20 \text { to } 70 \text {, and all education levels (high school - } \\
\text { PhD education level). These interviewees are quoted in the manuscript as } \\
\text { (Customer } 1 \text { - Customer } 38 \text { ). }\end{array}$ & $\begin{array}{l}\text { To receive explanations about the omni- } \\
\text { channels of the studied companies (e.g., } \\
\text { their channels and selling methods), } \\
\text { data capturing and sharing mechanisms, } \\
\text { the level of integration and } \\
\text { digitalization of their omni-channels, } \\
\text { IDTs used, and the challenges and } \\
\text { opportunities associated with them. } \\
\text { Also, to receive information about the } \\
\text { experience of consumers from omni- } \\
\text { channels and methods for receiving and } \\
\text { providing data from/to them during } \\
\text { their shopping experience. }\end{array}$ \\
\hline \begin{tabular}{|l|} 
Documentation \\
and archival \\
records
\end{tabular} & $\begin{array}{l}\text { - Websites of all participating companies ( } 17 \text { websites). } \\
\text { - Annual reports of } 17 \text { companies. } \\
-97 \text { internal reports of the companies about their omni-channels. } \\
\text { - } 56 \text { articles and white papers by the companies participating in this study and by } \\
\text { the leading industrial press about the omni-channels of the studied companies } \\
\text { and digitalization of their operations. } \\
\text { - Films from the companies showing how IDT, including IoT technology, BDA, } \\
\text { sensor-equipped RFID devices are used in omni-channel operations. }\end{array}$ & $\begin{array}{l}\text { Technical aspects of IDTs and the way } \\
\text { they capture, share and store data within } \\
\text { one company or among several } \\
\text { organizations in an omni-channel are } \\
\text { possible to be received via documents, } \\
\text { including technical reports with figures } \\
\text { and maps of the systems. These are } \\
\text { completing the qualitative data received } \\
\text { via other sources. } \\
\text { Details of the companies' performance } \\
\text { are gathered via their annual reports. } \\
\text { More details about the omni-channels } \\
\text { of the companies and their initiatives, } \\
\text { projects, and investments in IDT are } \\
\text { gathered via white papers, internal } \\
\text { reports and industrial articles } \\
\text { Documentation also enable data } \\
\text { triangulation. }\end{array}$ \\
\hline $\begin{array}{l}\text { Direct and } \\
\text { participant } \\
\text { observations }\end{array}$ & $\begin{array}{l}\text { Visiting five sites using IDTs for capturing information about products and cargo } \\
\text { including observation of: } \\
\text { - A port which is operating by using RFID tags on containers. } \\
\text { - RFID readers and sensors installed alongside rail tracks to receive verified } \\
\text { information from every RFID-tagged rail wagon in transportation. } \\
\text { - An IoT lab which visualizes and tests different types of tags and sensors to be } \\
\text { used in different kinds of environments for enabling connectivity of objects. } \\
\text { - Smart trays, using temperature sensor-equipped RFID tags, used for tracking } \\
\text { and tracing fresh seafood among several companies in a retail network. } \\
\text { - A distribution center in which RFID tag equipped pallets are handled by RFID } \\
\text { reading equipped lift trucks. }\end{array}$ & $\begin{array}{l}\text { Observations lead to a much deeper } \\
\text { understanding of the researchers about } \\
\text { the IDTs used in omni-channels and the } \\
\text { technical limitations associated with } \\
\text { each of them, the price of the } \\
\text { technology, and data sharing aspects } \\
\text { including trust and sharing } \\
\text { commercially sensitive data. } \\
\text { Observations also enable data } \\
\text { triangulation. }\end{array}$ \\
\hline Focus groups & $\begin{array}{l}\text { In total four focus group meetings with the participants of the IDT providers } \\
\text { (companies } 15-17 \text { ) take place including: } \\
\text { - First meeting with two researchers and } 11 \text { managers. The meeting lasts for four } \\
\text { hours. } \\
\text { - Second meeting with two researchers and } 8 \text { managers, which takes five hours. } \\
\text { - Third meeting, with two researchers and } 7 \text { managers, which lasts for four hours. } \\
\text { - Fourth meeting with } 2 \text { researchers and } 8 \text { managers, which takes four hours. }\end{array}$ & $\begin{array}{l}\text { Providing important insights regarding } \\
\text { inter-organizational aspects of data } \\
\text { management and IDT used for it in } \\
\text { omni-channels (e.g., inter-operability of } \\
\text { databases of companies when } \\
\text { exchanging data) by presenting and } \\
\text { discussing the perspectives of their } \\
\text { companies. These meetings help to } \\
\text { identify the suitable companies and } \\
\text { sectors to focus on. } \\
\text { They lead to improving the findings and } \\
\text { propositions of the study. } \\
\text { Furthermore, they enable data } \\
\text { triangulation. }\end{array}$ \\
\hline
\end{tabular}


C1 "I go to the store to see the product physically and eventually try it on. Then I prefer to buy online both because I can think about Cu1 it and because it is very convenient to receive the product directly at home."

"I believe the opening of pop up stores can bring us back to the public and enable businesses to get more public attention."

"Augmented reality is a new way of trying products - closest to physically trying the products. Just select a pair of shoes of your choice from the digital catalog, point the iPhone camera at your right leg and a simulation of how the sneaker would look will be shown."

"One of the things that I like the most about searching online is the possibility to read other consumers' reviews. I think that the enthusiasm or the disappointment expressed by another person is affecting my choice."

"[social media] influencers try clothes and share it with us, which is affecting my decision to buy them."

"I like seeing these advertisements on social media because I am looking for something that is kind of entertaining. So, if I see something with those characteristics, I will check out the product and click on the link in the ad that takes me directly to the online store ..."

"I often purchase on multi-brand websites because they offer great discounts and more product stock variety."

"I find some Instagram adverts useful, because they suggest me products that I am looking for."

"I am surprised that companies have so much information about me."

C2 "I never read the terms and conditions. I just check the box with the agreement."

"Often I save the terms and conditions on my desktop, but then I delete them after a while without reading them."

"If you have different payment apps like PayPal, I would prefer that one, rather than putting my entire credit card details."

C3 "Often a questionnaire is sent asking about the shopping experience. I answer the quick and easy ones but ignore the time-taking surveys"

C4 "I prefer to buy from only one retailer because I know their terms and conditions. Because different online retailers have different Cu14 return terms and conditions and I do not have time to go and review all of them."

"I buy from companies who have an easy and straightforward return...If a company gives vouchers for returned items or if I Cu15 should pay for posting the product back then I don't buy from them unless their price is very low."

R1 "Having a deep understanding of your customers and market is a part of the success of omni-channel retailing." "Analyzing data on Facebook and Twitter is one way of understanding the market ... there are [other] ways too. For example, the best way of Co13 learning about the needs of customers of running shoes and clothing is arranging group running events and working with coaches."

R2 "Currently they manage to pull together overviews of demand data very manually from across different silos and Excel spreadsheets" ... Co10 "one of our DCs alone has 3,500 suppliers; some data consolidation is conducted but we need to do more [on data management]."

"For wholesale accounts replenishment is carried out through a B2B platform where they can see inventory availability and place orders." Co11

"At the moment retailers are putting pressure on suppliers to take more responsibility for a master data set-up, ordering all of Co1 those transaction elements of the supply chain."

"Having correct handling [requirements] information will lead to better movement of products in our supply chain."

"[after the order is placed] products go into a black hole until when they are ready to ship."

$\operatorname{Cos}$ same as the information that has been sent through the ASN message. So, there are process checks that you can have in place to ensure that the right information is going to the customer at the right time."

"UPS use their own track and trace - they have a current pilot in place for own track and trace system."

"Customer home delivery orders go out by $A A A$ Mail currently. They use an Access data base from the warehouse to manage Co10 online orders - They wanted to switch carriers to $[X Y Z$ Logistics] but the Access database can't integrate with Hermes so stuck with [AAA Mail] (and $[B B B$ Mail $]$ for next day deliveries)."

"Track and trace is in place and is all managed through SAP [Enterprise Resource Planning system]. Logistics [Department] is Co11 working with the purchasing team much more closely on managing logistics data."

"We have a 2 year project to replace all systems - store EPOS and ERP and planning/warehousing systems ...Vendor selection Co10 has been made... End to end integrated system will allow real time view of stock. Currently they manage to pull together overviews of data very manually from across different silos/Excel spreadsheets."

R3 "Proposition and the requirements (e.g. costs involved in meeting two hour delivery slots from point of order) - customers are now more savvy, especially when they don't need it immediately; however this shifts in the week pre-Christmas where customers are now very demanding." "Anything that can reduce the amount of [data] errors will only help the relationship."

R4 "Returns is a huge challenge in omni-channel retail. ... no visibility about how many times a thing [item] was returned leads to Co9 lack of control on our [operations] costs."

"We don't have visibility of what is being returned until it turns up at the warehouse."

"... product data changes through different stages of the omni-channel."

"GTIN is fundamental to our many scanning processes; [It is] used on either individual units or cartons, whatever the product is moving." "Barcodes are placed at point of origin, for other brands [we need to] often relabel [products] with the [Company 11] SKU number."

"Barcodes enable semi-automation... [and] RFID would give more 'warehouse' style stock accuracy on the shop floor which will improve fulfillment". "Hierarchies of scanning from unit to box to pallet to truck [is done by barcode and] we would like to do the same with RFID where appropriate."

Consumer Data

"When collecting consumer data, [Company 2] complies with applicable privacy legislation and regulations, and applies

[Company 2] standards where specific regulation is not yet in place. The [Company 2] Data Collection Guidelines also include specific guidance on data collection from children."

"We take protecting consumer personal information seriously and are continuously developing our security systems and Co20 processes. Some of the controls we have in place are:... We use technology controls for our information systems, such as firewalls, user verification, strong data encryption, and separation of roles, systems \& data ... Systems are proactively monitored through a "detect and respond" information security function"

Business Unit Data

"[Company 1] uses a single Global Location Number (GLN), a code that uniquely identifies [an omni-channel] member Co1 organization, for its entire product range."

"[Company 2] is participating in the United Nations' (UN) "Blue Number" program... that gives farmers an online presence,... connects them to buyers... also assigns a unique global location number (GLN) to farmers around the world.

"The [planning] information exists, but not under one umbrella."

"Currently we manage to pull together overviews of [planning] data very manually from across different silos/Excel spreadsheets." Co10

Delivery Data

"We have EDI set up with 3PL to feed data into whatever WMS system they are using."

"Customer home delivery orders go out by Royal Mail currently. They use an Access data base from warehouse to manage Co10

online orders - They wanted to switch carriers to Hermes but the Access database can't integrate with Hermes so stuck with

Royal Mail (and UK mail for next day deliveries).'

"WMS different case by case - if not SAP then have EDI set up with 3PL so feed data into whatever WMS system they are using."

* Associated with the consumer journey and retailer steps in Figures 1 and 2, and data types in Section 4.3. 
Table IV. The case study research quality tests according to Yin (2014), and the way the tactics related to each of them are used in this research.

\begin{tabular}{|c|c|c|}
\hline Tests & Implementation of the tactics related to the tests in this research & $\begin{array}{l}\text { Stage of } \\
\text { implementation }\end{array}$ \\
\hline $\begin{array}{l}\text { Construct } \\
\text { validity }\end{array}$ & $\begin{array}{l}\text { - Multiple sources of evidence (interviews, documentations, focus groups and observations) are used, } \\
\text { enabling data triangulation. } \\
\text { - Chain of evidence is created and used when collecting data, by identifying different agents of omni- } \\
\text { channels, the types of data which they provide and receive, the IDTs used for managing their data } \\
\text { flows, and the governance mechanisms required to manage their relationships . } \\
\text { - Company representatives review and confirm the findings of the study before finalizing and publishing } \\
\text { the outcomes. }\end{array}$ & - Composition \\
\hline $\begin{array}{l}\text { Internal } \\
\text { validity }\end{array}$ & $\begin{array}{l}\text { - Key theme-matching and coding, with support of the key literature, are done when analysing data. } \\
\text { - Explanations are built, highlighting the connections among the omni-channel data flows, agents, IDTs, } \\
\text { and inter-organizational governance mechanisms. } \\
\text { - Theoretical associations are made both at within-case and cross-case levels, as a basis for pattern } \\
\text { matching. }\end{array}$ & Data analysis \\
\hline $\begin{array}{l}\text { External } \\
\text { validity }\end{array}$ & $\begin{array}{l}\text { - Well defined criteria are used for case studies selection - as explained in Section } 3.1 \text {. } \\
\text { - Multiple case studies (totally 17), from a range of industries, and from various omni-channel agents, as } \\
\text { well as interviews with both businesses and consumers strongly support the research generalizability. }\end{array}$ & Research design \\
\hline Reliability & $\begin{array}{l}\text { - Case study protocol is developed and used in a systematic way. } \\
\text { - A case database is created in which all the data (interview files and transcripts, documents and meeting } \\
\text { recordings and notes) are stored. }\end{array}$ & Data collection \\
\hline
\end{tabular}


Figure 1a:

Grewal and Roggeveen, (2020); Lemon and Verhoef (2016); Tueanrat et al.(2021)

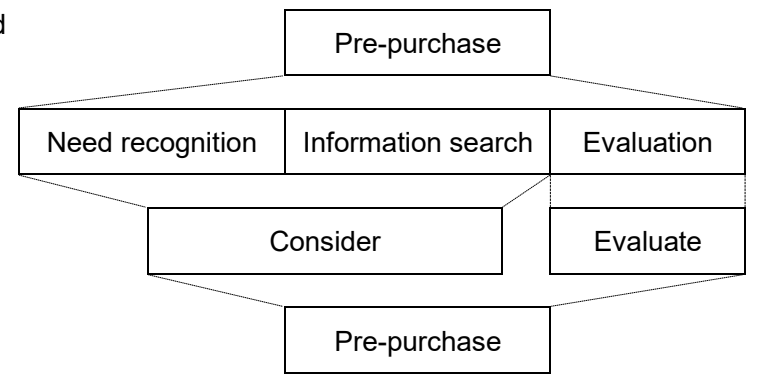

\begin{tabular}{|l|l|}
\hline \multicolumn{2}{|c|}{ Post-purchase } \\
\hline $\begin{array}{c}\text { Post-purchase } \\
\text { evaluation }\end{array}$ \\
\hline \\
\hline Delivery & Return \\
\hline
\end{tabular}

Emphasizes the purchasing decision, what is needed before it, and what happens after it

More focused on the consumer psychology and actions prior to purchase commitment

Biased toward pre-purchase steps, lacks the post-purchase steps

Focused on physical flows across channels, and emphasizes the post-purchase logistics

\section{Figure 1b:}

\section{Reference}

Croxton's (2003)

Zhu et al. (2021)

Leung et al. (2018)

Zhang et al. (2019)-Core:

Supportive:
Distinguished Consumer Shopping Steps

\begin{tabular}{|c|}
\hline $\begin{array}{c}\text { Market } \\
\text { review }\end{array}$ \\
\hline $\begin{array}{c}\text { Market } \\
\text { analysis }\end{array}$ \\
\hline $\begin{array}{c}\text { Launching } \\
\text { sales platforms }\end{array}$ \\
\hline
\end{tabular}

$$
\begin{aligned}
& \text { Launching } \\
& \text { sales platforms }
\end{aligned}
$$

\begin{tabular}{|c|}
\hline $\begin{array}{c}\text { Receiving (defining) } \\
\text { order }\end{array}$ \\
\hline $\begin{array}{c}\text { Order } \\
\text { processing }\end{array}$ \\
\hline $\begin{array}{c}\text { Receiving } \\
\text { orders }\end{array}$ \\
\hline Order receipt \\
\hline Inventory management \\
\hline
\end{tabular}

\begin{tabular}{|c|}
\hline $\begin{array}{c}\text { Planning order } \\
\text { fulfillment }\end{array}$ \\
\hline $\begin{array}{c}\text { Picking \& } \\
\text { packing }\end{array}$ \\
\hline $\begin{array}{c}\text { Internal order } \\
\text { processing }\end{array}$ \\
\hline Pick \& pack \\
\hline Warehousing \\
\hline
\end{tabular}

\begin{tabular}{|c|}
\hline $\begin{array}{c}\text { Logistics network } \\
\text { evaluation }\end{array}$ \\
\hline Delivery \\
\hline $\begin{array}{c}\text { Outbound } \\
\text { delivery }\end{array}$ \\
\hline Shipment \\
\hline Delivery \\
\hline
\end{tabular}

Covers a range of activities, from market review to product delivery

Covers a range of activities (marketto-delivery) for online order fulfillment

Covers a range of activities (marketto-delivery) for online order fulfillment

Analyses the retailer's order

fulfillment based on core \& supportive activities including after-sales

Figure 1. Mapping the literature of consumer shopping journey and retailer main steps. 


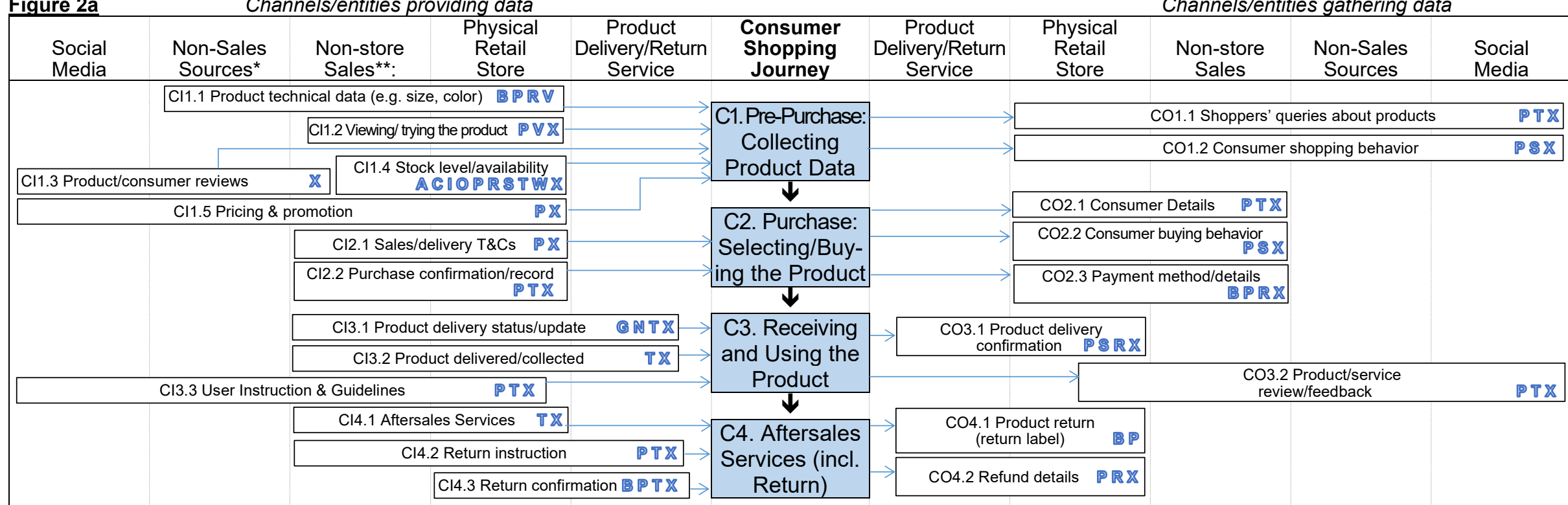

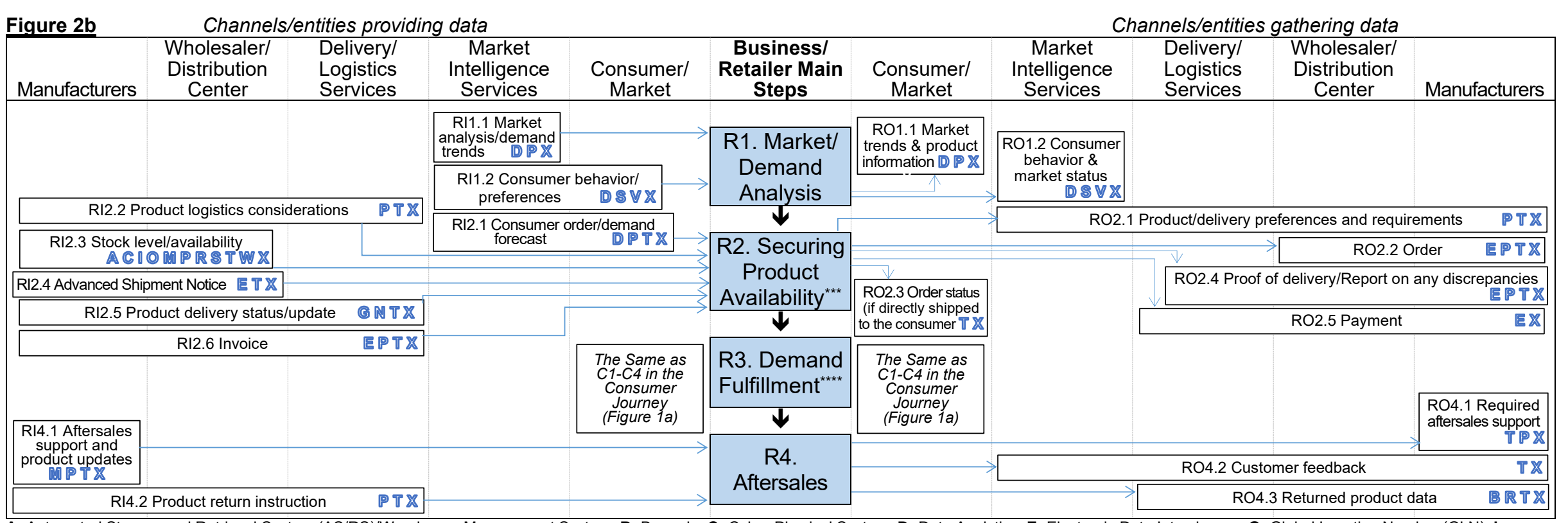

A: Automated Storage and Retrieval System (AS/RS)/Warehouse Management System; B: Barcode; C: Cyber Physical System; D: Data Analytics; E: Electronic Data Interchange; G: Global Location Number (GLN); I: Internet-of-Things; M: Manufacturing Resource Planning/Enterprise Resource Planning; N: Sat-Nav; O: Object Recognition Technology; P: Paper-based/visual data; R: RFID/Read \& Write Device; S: Smart Sensors/smart

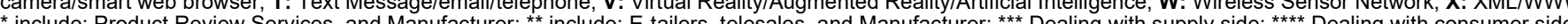

Figure 2. Omni-channel data flows - (a) consumer perspective (CI: consumer input data, CO: consumer output data); (b) business perspective (RI: retailer input data, RO: retailer output data). 


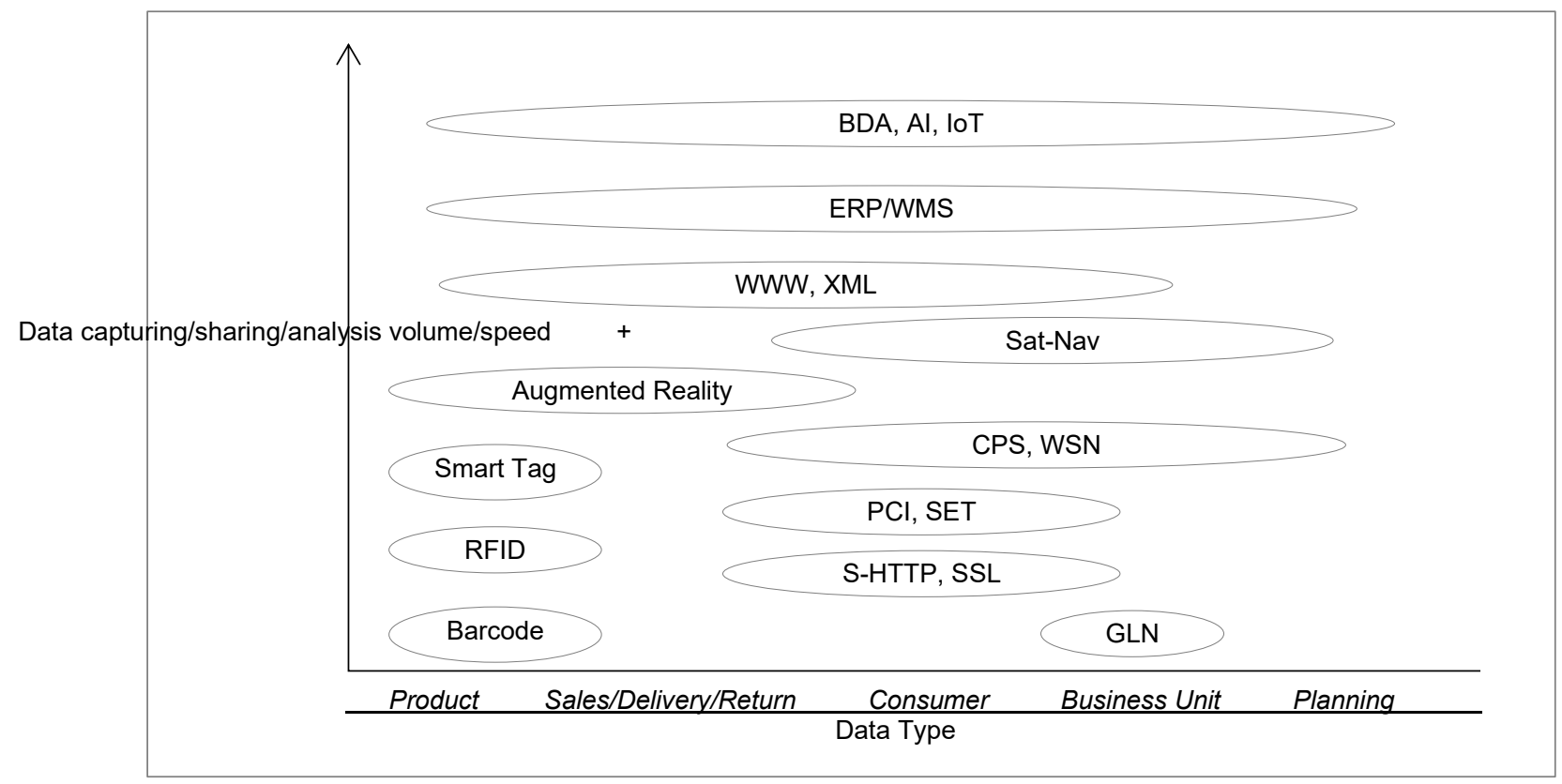

Figure 3. An illustrative IDT capability to capture, share and analyze different data type. 


\section{Figure 4a}

Consumer feedback about the product is analyzed and passed to the manufacturer (Co11)

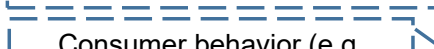
trying the product in store and buying it online) is shared with the relevant channels (Co14)
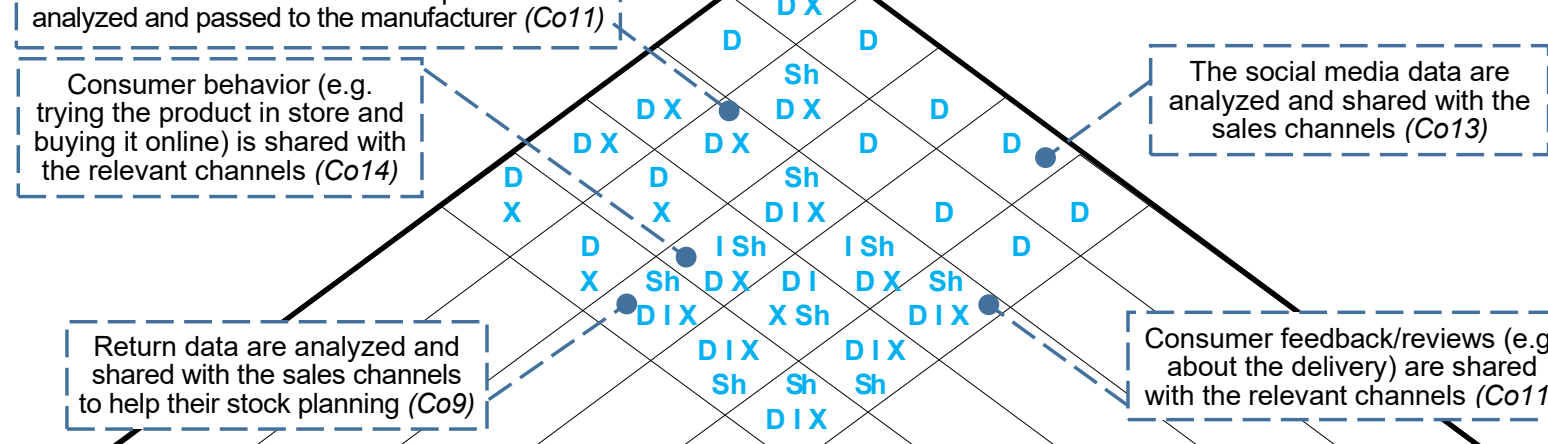
DXX

\begin{tabular}{|c|c|c|c|c|c|c|c|c|c|c|}
\hline $\begin{array}{l}\text { Social } \\
\text { Media }\end{array}$ & $\begin{array}{l}\text { Non-Sales } \\
\text { Sources: }\end{array}$ & $\begin{array}{l}\text { Non-store } \\
\text { Sales }\end{array}$ & $\begin{array}{c}\text { Physical } \\
\text { Retail } \\
\text { Store }\end{array}$ & $\begin{array}{c}\text { Product } \\
\text { Delivery/ } \\
\text { Return } \\
\text { Service } \\
\end{array}$ & $\begin{array}{c}\text { Consumer } \\
\text { Shopping } \\
\text { Journey }\end{array}$ & $\begin{array}{c}\text { Product } \\
\text { Delivery/ } \\
\text { Return } \\
\text { Service } \\
\end{array}$ & $\begin{array}{c}\text { Physical } \\
\text { Retail } \\
\text { Store }\end{array}$ & $\begin{array}{c}\text { Non-store } \\
\text { Sales }\end{array}$ & $\begin{array}{c}\text { Non-Sales } \\
\text { Sources }\end{array}$ & $\begin{array}{l}\text { Social } \\
\text { Media }\end{array}$ \\
\hline & \multirow{2}{*}{\multicolumn{3}{|c|}{\begin{tabular}{|c|}
$\begin{array}{c}\text { Cl1.1 Product technical data (size, } \\
\text { functions, material, colour ...) }\end{array}$ \\
\end{tabular}}} & & \multirow{2}{*}{$\begin{array}{l}\text { C1.Pre- } \\
\text { Purchase: }\end{array}$} & & & \multicolumn{2}{|c|}{ C01.1 Shoppers' queries about products } & \\
\hline & & & & & & & & C01.2 Consumer & $\| A$ & \\
\hline
\end{tabular}

\section{Figure 4b}

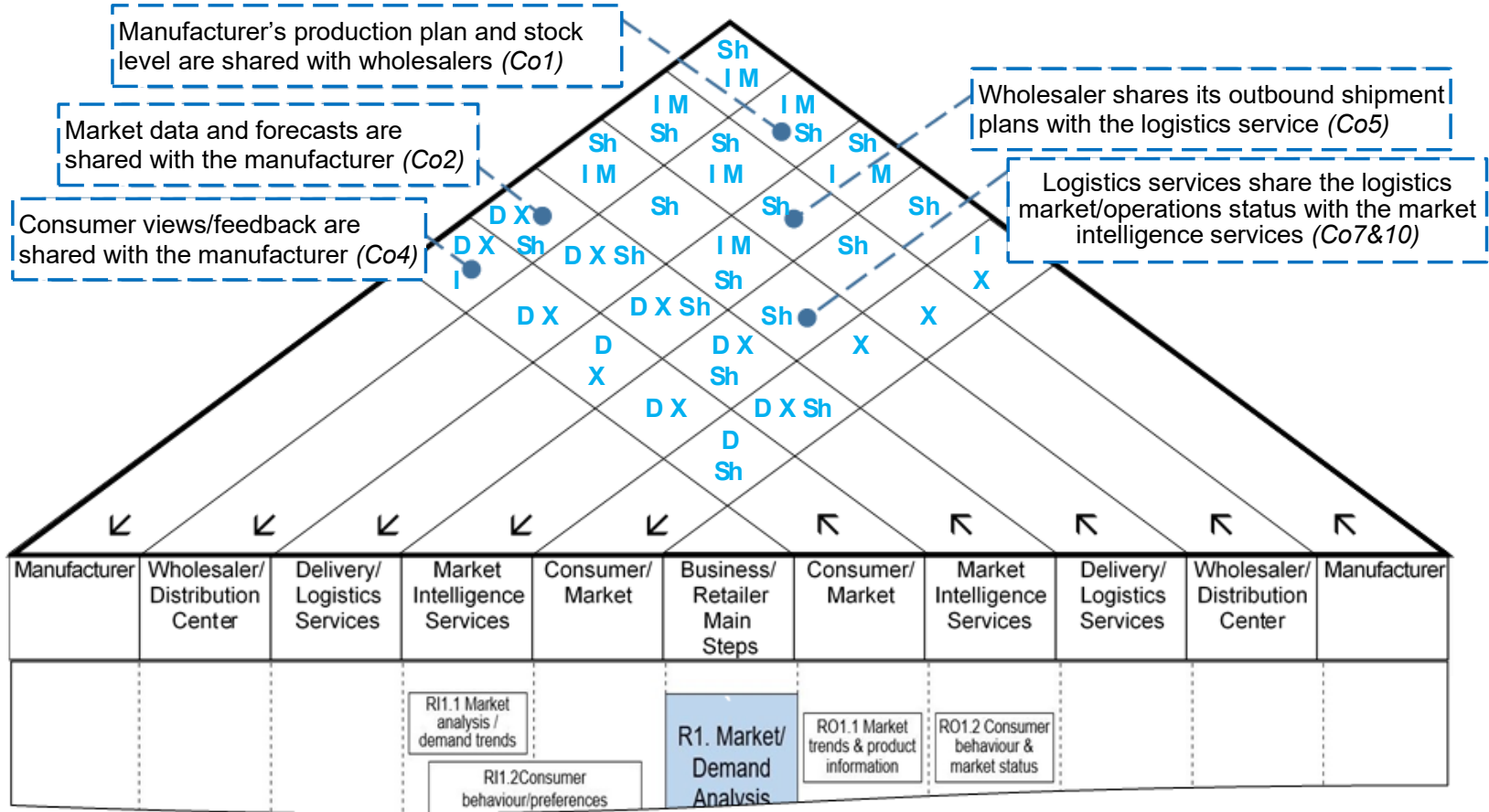

D: Data Analytics; I: Internet-of-Things; M: Manufacturing Resource Planning/Enterprise Resource Planning; Sh: Shared databases; W: Wireless Sensor Network; X: XML/WWW

Figure 4. Total integration on, (a) consumer side, (b) business side. 


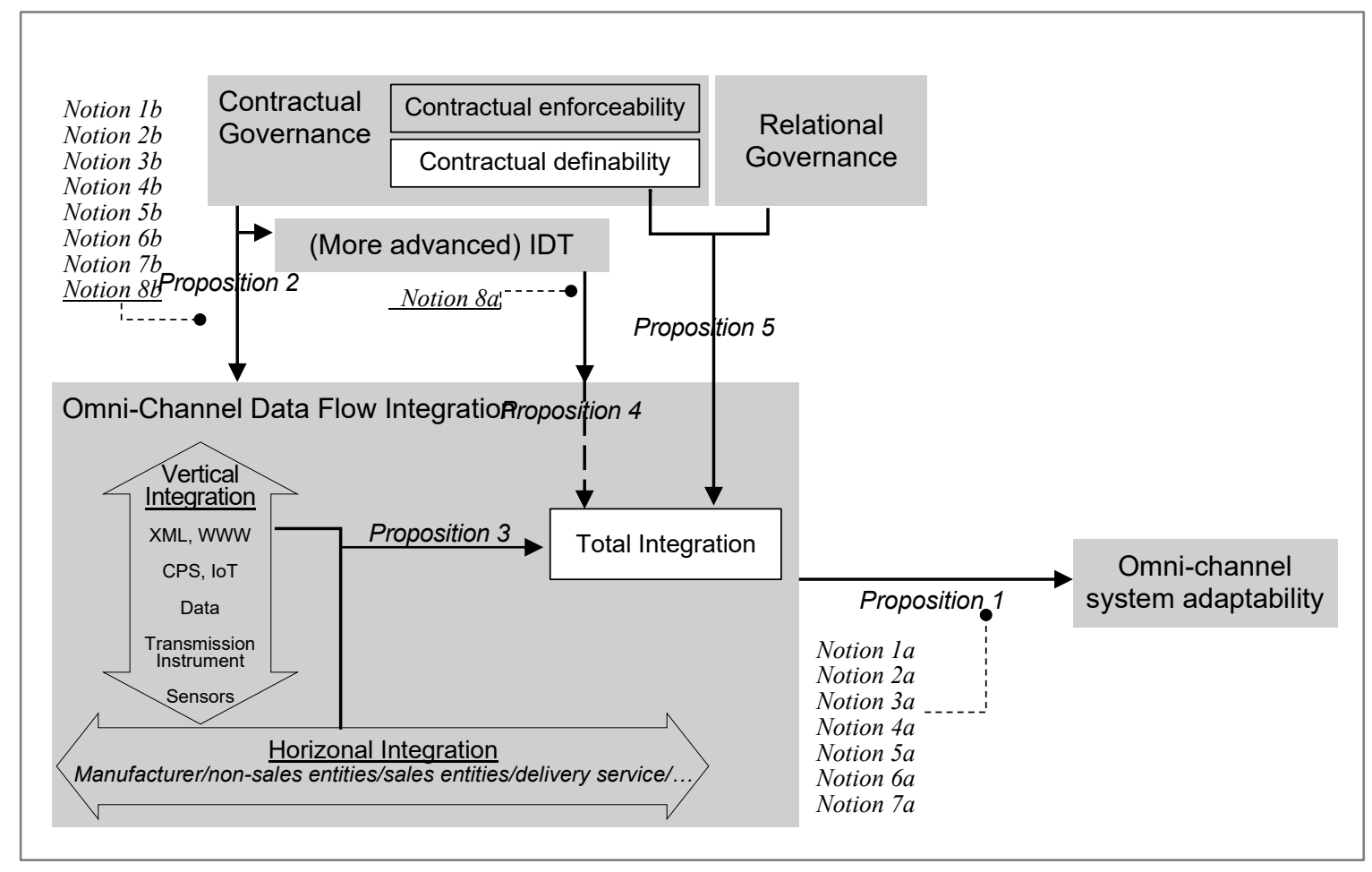

Figure 5. Research propositions and theoretical framework. 